\title{
An Efficient Linear Algebraic Algorithm for the Determination of Isomorphism in Pairs of Undirected Graphs
}

\author{
Charles R. Johnson* and Frank Thomson Leighton \\ Institute for Basic Standards, National Bureau of Standards, Washington, D.C. 20234
}

(September 29, 1976)

An algorithm, complete with a specific FORTRAN implementation, is presented for the problem of determining whether or not two undirected graphs are isomorphic. The algorithm, centered upon the eigenvalues and eigenvectors of a modified adjacency matrix and techniques for decreasing the size of the automorphism group, is quite different from others (most of which are combinatorially based) and tends to work relatively very quickly on difficult test cases as well as on typical examples. Complexity estimates are given for many eventualities.

Key words: Graph isomorphism; labels; modified adjacency matrix; spectrum.

\section{Introduction}

Two undirected graphs are said to be isomorphic if there exists a one-to-one correspondence between their nodes which preserves adjacency. A computationally difficult issue in the theory of graphs is the determination of isomorphism. For example the graphs in figure la are pairwise isomorphic while those in $\mathrm{lb}$ are not.
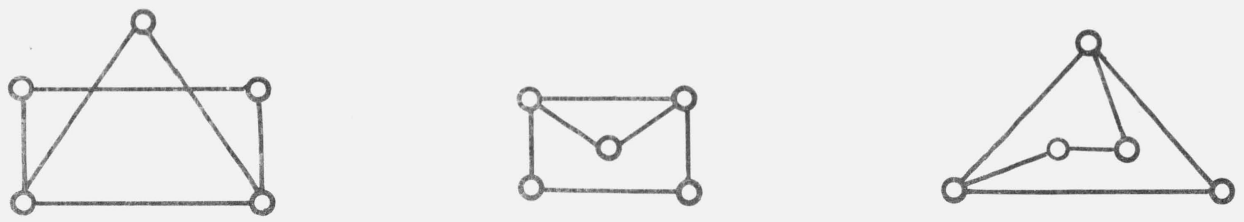

Figure 1a<smiles>O=c1ooo1</smiles>

Figure 1b

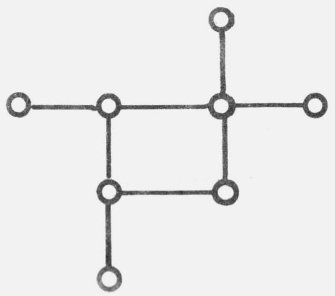

AMS Subject Classification: $68 \mathrm{~A} 10$ 05C99, $65 \mathrm{~F} 99$.

* Present address: Institute for Physical Science and Technology, University of Maryland, College Park, Md. 20742. 
The ability to divide a set of graphs into maximal subsets whose elements are pairwise isomorphic has several immediate applications. If nodes are identified with atoms of a particular compound and if edges are identified with the existence of a chemical bond, then, for instance, such an ability is of use to the chemist in distinguishing among many theoretically produced compounds. Other applications include physics (e.g. "hearing" the shape of a drum [1] $)^{1}$, electronic circuit theory, linguistics etc.

Much effort has been devoted to the development of an algorithm which will determine whether or not any two graphs are isomorphic in an amount of time that is bounded by a finite polynomial in the number of nodes of the graphs considered. At the moment, the authors are unaware of the existence of any such algorithm. Many approximate or heuristic procedures have been developed however. Many such algorithms check conditions combinatorially necessary for isomorphism, some also attempt to construct a permutation that would exhibit isomorphism. Corneil presents a review of many such techniques. All known exact methods grow exponentially in required time. Unfortunately, as pointed out in [4] such procedures could take very long to determine whether or not two graphs of order 15 are isomorphic. Hence, such methods are clearly inadequate for large order graphs.

If a computer is to be used to determine whether or not two graphs are isomorphic, the graphs must be represented in a form suitable for machine processing. The adjacency matrix of a graph is such a standard form. First, the nodes of the graph are arbitrarily associated with the integers $1,2,3 \ldots n$ where $n$ is the order of the graph. The $(i, j)$ component of the adjacency matrix is then defined to be 1 if there is an edge connecting the $i$ th node and the $j$ th node and is 0 otherwise. The $(i, i)$ entry commonly contains the label given the node. In the case of an unlabeled graph, $(i, i)$ entries are typically zero. While different orderings of the nodes produce different adjacency matrices, two adjacency matrices are isomorphic if and only if, independent of labeling, they correspond to the same graph. Figure 2 illustrates this.

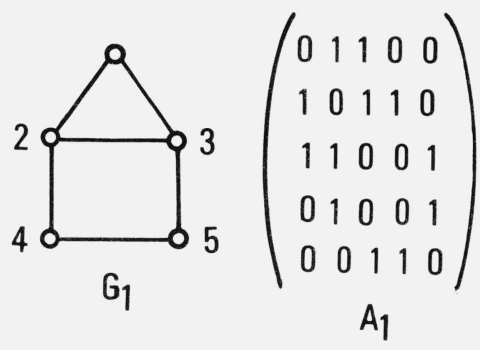

Figure 2a

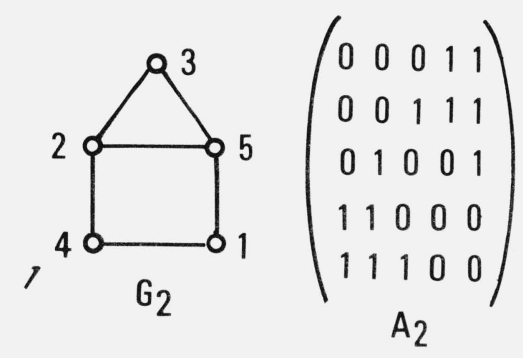

Figure $2 b$

$$
A_{2}=p^{\top} A_{1} P \text { Where } P=\left(\begin{array}{lllll}
0 & 0 & 1 & 0 & 0 \\
0 & 1 & 0 & 0 & 0 \\
0 & 0 & 0 & 0 & 1 \\
0 & 0 & 0 & 1 & 0 \\
1 & 0 & 0 & 0 & 0
\end{array}\right)
$$

Figure 2c

The algorithm about to be described is divided roughly into three sections each satisfying a specific purpose. The first section consists of several basic tests for nonisomorphism. These tests are all $0\left(n^{3}\right)$ or better and are surprisingly effective in distinguishing nonisomorphic graphs. Since nearly all pairs of graphs that pass through the initial tests undistinguished are likely to be isomorphic, the second part of the algorithm involves the attempted construction of a permutation between the adjacency matrices of the graphs. In the great majority of cases, this is easily and quickly accomplished. The second section simultaneously serves as a more complicated test for nonisomorphism should it be found impossible to generate a satisfactory permutation.

\footnotetext{
${ }^{1}$ Figures in brackets indicate the literature references at the end of this paper.
} 
The final section is specifically designed to deal with certain classes of matrices that do not easily yield to the tests or efforts to construct a permutation found in the previous two components. In general the tests in this section are more time consuming, generally $0\left(n^{4}\right)$, and are quite detailed. Methods of finding a satisfactory permutation are included as well as tests for nonisomorphism.

A complete FORTRAN listing of the algorithm, including explanatory comments, follows its description in section 3 and the test results provided in section 4 demonstrate the efficiency of the algorithm.

\section{The Algorithm}

Initially, the algorithm employs four basic tests, each of which checks for the failure of a condition necessary for isomorphism. The first test determines whether or not the node labels of the two graphs are identical. If they are not, then the corresponding graphs are not isomorphic. In the case of unlabeled graphs, the test yields no information and is unnecessary. This test is performed by SUBROUTINE LABEL and takes $0\left(n^{2}\right)$ amount of time when $n$ is the order of the graphs.

A more useful test involves the comparison of the node valences of the two graphs. The valence of a node is the number of edges connected to it. The valence of each node, once computed, is combined with the node's label to form a new label for that node. Two nodes of a graph will have the same new label if and only if they have the same valence as well as identical initial labels. Thus two graphs with different sets of new labels are themselves nonisomorphic. For example, the graphs in figure 3 share the same set of node valences and of initial labels yet when these two qualities are considered mutually, the graphs are found to be nonisomorphic.
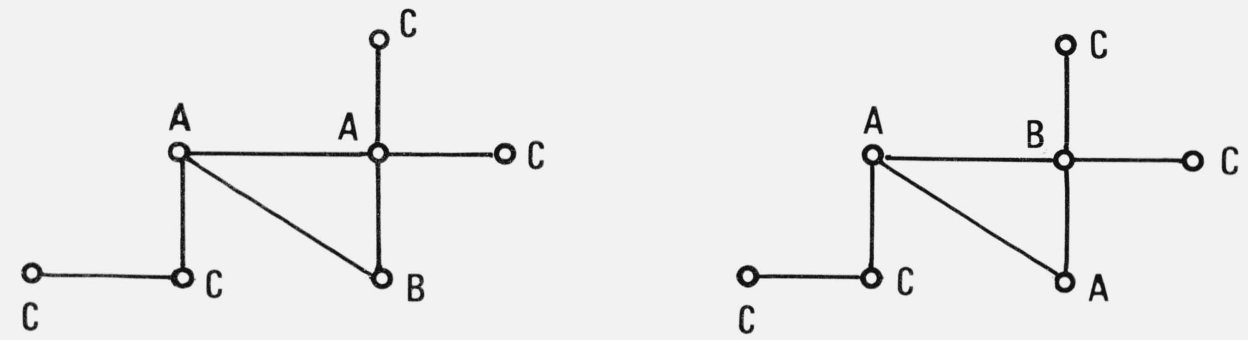

Figure 3

The set of initial node labels is $(A, A, B, C, C, C, C)$ for each graph. Similarly the set of node valences is $(1,1,1,2,2,3,4)$ in each case. When combined to produce sets of new labels, however, the following two distinct sets are formed: $(\mathrm{A} 3, \mathrm{~A} 4, \mathrm{~B} 2, \mathrm{Cl}, \mathrm{C} 1, \mathrm{C} 1, \mathrm{C} 2)$ and $(\mathrm{A} 2, \mathrm{~A} 3, \mathrm{~B} 4, \mathrm{C} 1, \mathrm{C} 1, \mathrm{C} 1, \mathrm{C} 2)$. Since these two sets are clearly not identical, the two graphs are not isomorphic. This test takes $0\left(n^{2}\right)$ time and is performed in SUBROUTINE VALENC.

The third basic test involves the search for and labeling of duplicate nodes. A given node is called an ordinary duplicate of degree $k$ if there exist $k-1$ and no more than $k-1$ other identically labeled nodes in the graph which are connected by edges to the same nodes as is the given node. A given node is called a connected duplicate of degree $k$ if the $k-1$ nodes just mentioned are all mutually connected. To further illustrate consider the graph in figure 4. The numbers are only for use in referencing the nodes while the letters correspond to actual labels.

Nodes 1 and 3 are connected duplicates of degree 2. Nodes 2 and 4 are ordinary duplicates of degree 2. Nodes 6 and 7 are not duplicates since they have different labels. Finally nodes 10,11 , and 12 are ordinary duplicates of degree 3 . All other nodes are trivially duplicates of degree 1 .

Node duplicate degrees are easily found from the 0,1 adjacency matrix of a graph. Groups of ordinary duplicate nodes correspond to groups of identical rows (with identical labels) of the adjacency matrix with 0 's entered on the diagonal. If l's are entered on the diagonal, then the connected duplicates can be similarly found. It is easily seen that two graphs are not isomorphic if the ordinary and connected duplicate degrees of their nodes differ in any manner. 


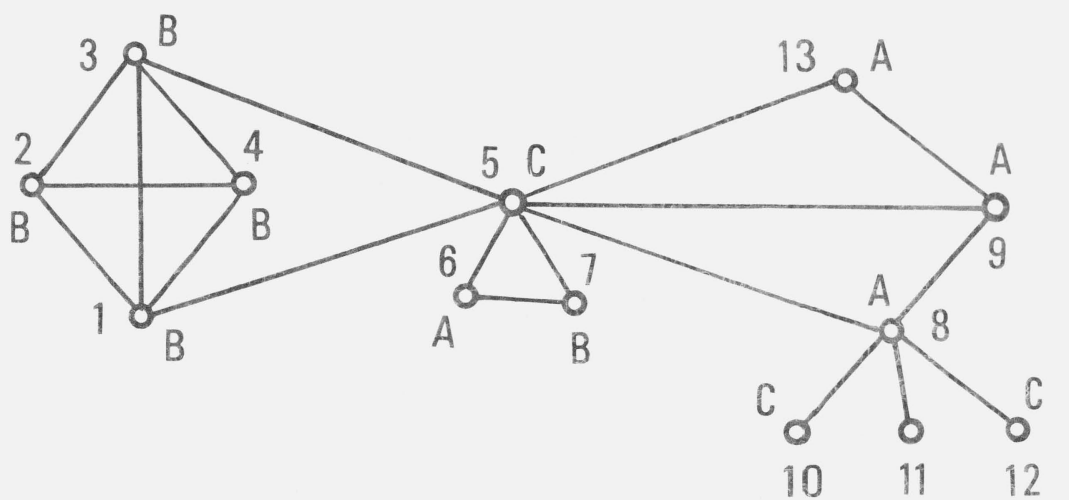

Figure 4

As before, the node labels of each graph are updated to reflect the newly obtained information and then compared. This is done in SUBROUTINE DUPLIC and takes $0\left(n^{3}\right)$ time.

While the identification of duplicate nodes serves as a worthwhile test for nonisomorphism, a potentially much more useful purpose is also served. A graph with a large number of nodes with duplicate degrees greater than one yields an adjacency matrix, $A$, and a large number of nontrivial automorphisms, that is permutations $P$ such that $P^{T} A P=A$. For reasons explained further on, graphs whose adjacency matrices have this property are especially difficult to analyze and any procedure which efficiently reduces the number of such permutations through appropriate labeling of the nodes of the graph, will greatly reduce the complexity of following computations. Labeling of duplicate nodes was found to be a particularly fast and simple way to achieve this end for many graphs. It should be noted that this labeling alone does not necessarily reduce the automorphism group to the identity.

A well-known necessary condition for isomorphism involves the comparison of spectra (set of eigenvalues) of the 0,1 adjacency matrices of two graphs. Much effort has been devoted to nonisomorphic pairs for which the 0,1 adjacency matrices have the same spectrum. Such pairs of graphs are called cospectral [5]. Many cospectral pairs of graphs are distinguishable, however, through comparison of the spectra generated from adjacency matrices with numbers different from 0,1 used to represent nonedges and edges [6]. It appears that the use of 0 and 1 in the computation of the spectra of graphs ignores much of their inherent structure. A greater amount of information about the graph can be discovered from the examination of the spectra of adjacency matrices with 1's representing no edges, and a variable $x$ representing an edge. Due to the nature of the characteristic polynomial, no generality is lost by replacing $x$ with either a transcendental number or certain large functions of the number of nodes in the graph. Unfortunately neither option is feasible for use with the computer since a transcendental number is truncated to a rational and a large value of $x$ yields errors in computation small in comparison to $x$ but large in comparison to 1 . A compromise solution was developed that allows $x$ to be a function that increases linearly with the order of the graph yet is essentially as effective in distinguishing nonisomorphic graphs as is the more general procedure.

In order to utilize the information stored in the updated labels of the nodes, the diagonal elements of the adjacency matrices are assigned the value of the appropriate label. The eigenvalues of each modified adjacency matrix are then computed and compared. Should the resulting spectra not be identical, the graphs are not isomorphic. The preparation of the adjacency matrices for eigenvalue computation is effected in SUBROUTINE PREPAR and takes $0\left(n^{2}\right)$ time. The computation of the eigenvalues as well as the eigenvectors (for future use) of each matrix is carried out in SUBROUTINE SPECTR and takes $0\left(n^{3}\right)$ time.

Since two graphs that are not distinguished by the preceding sequence of tests may well be isomorphic, it is reasonable at this point to attempt to generate a permutation that relates the two graphs. The number of such possible permutations can be greatly limited with efficient use of the information stored in the eigenvectors of the two adjacency matrices. If $A$ and $B$ are two symmetric matrices with identical spectra then there exist orthogonal matrices $U$ and $V$ and a diagonal matrix $D$ such that

$$
U^{T} A U=D \quad \text { and } \quad V^{T} B V=D .
$$


Further assuming that $A$ and $B$ are permutationally equivalent we have $B=P^{T} A P$ where $P$ is a permutation matrix. Then:

$$
\begin{aligned}
U^{T} A U & =V^{T} P^{T} A P V \\
D & =V^{T} P^{T} U D U^{T} P V \\
U^{T} P V D & =D U^{T} P V
\end{aligned}
$$

and thus $D$ commutes with $E=U^{T} P V$.

If $E=\left(e_{i j}\right)$ and $D=\left(d_{i j}\right)$ with $d_{i j}=0$ for $i \neq j$, then $D E=\left(d_{i i} e_{i j}\right)$ and $E D=\left(d_{j j} e_{i j}\right)$. Thus if $d_{i i} \neq d_{j j}$, then $d_{j j} e_{i j}=d_{i i} e_{i j} \rightarrow e_{i j}=0$.

Thus $E=$

$$
\left(\begin{array}{ccccc}
E_{1} & & & & \\
& E_{2} & & & 0 \\
& & \cdot & & \\
0 & & \cdot & \\
& & & \cdot & \\
& & & & E_{m}
\end{array}\right)
$$

where $E_{i}$ is an orthogonal matrix of degree equal to the multiplicity of the $i$ th distinct eigenvalue of $A$.

The relation $U E=P V$ serves to greatly restrict the number of permutations, $P$. Consider first the restrictions imposed by the existence of eigenvalues of multiplicity one. In this case, the corresponding matrix $E_{i}$ is trivially $(1)$ or $(-1)$. Thus for each $j$ such that $d_{j j}$ is unique, we know that the set of permutations of

$$
\begin{gathered}
{\left[\begin{array}{c}
u_{1 j} \\
u_{2 j} \\
\cdot \\
\cdot \\
u_{n j}
\end{array}\right] \text { into }\left[\begin{array}{c}
v_{1 j} \\
v_{2 j} \\
\cdot \\
\cdot \\
\cdot \\
v_{n j}
\end{array}\right] \text { combined with }} \\
\text { those of }\left(\begin{array}{c}
-u_{1 j} \\
-u_{2 j} \\
\cdot \\
\cdot \\
-u_{n j}
\end{array}\right] \text { into }\left(\begin{array}{c}
v_{1 j} \\
v_{2 j} \\
\cdot \\
\cdot \\
v_{n j}
\end{array}\right] \text { include }
\end{gathered}
$$

all permutations of $A$ into $B$.

$$
\left[\begin{array}{c}
u_{1 j} \\
u_{2 j} \\
\cdot \\
\cdot \\
u_{n j}
\end{array}\right] \text { and }\left[\begin{array}{c}
v_{1 j} \\
v_{2 j} \\
\cdot \\
\cdot \\
\cdot \\
v_{n j}
\end{array}\right] \text { are simply the }
$$

eigenvectors of $A$ and $B$ corresponding to the eigenvalue $d_{j j}$ and are easily computed.

Since the components of the eigenvectors of most modified adjacency matrices are unique, ne number of possible permutations of $A$ into $B$ is small. In these cases, all possible permutations are quickly generated and checked until one is found that relates $A$ and $B$ or until the supply is exhausted. In the latter case, the graphs are not isomorphic.

As was mentioned earlier graphs that yield an adjacency matrix, $A$, and several permutations, $P$, such that $P^{T} A P=A$ are very difficult to work with. The reason for this phenomenon now becomes apparent. If the number of permutations of $A$ into itself is large, then there will be many pairs of $k$ and $l$ such that $u_{k j}=u_{i j}$ for every $j$ such that $d_{j j}$ is unique. This, in turn, greatly increases the number of permutations 


$$
\text { of }\left[\begin{array}{c}
u_{1 j} \\
u_{2 j} \\
\cdot \\
\cdot \\
u_{n j}
\end{array}\right] \text { into }\left(\begin{array}{c}
v_{1 j} \\
v_{2 j} \\
\cdot \\
\cdot \\
v_{n j}
\end{array}\right) \text { and thus }
$$

the amount of time which may be required to find a permutation of $A$ into $B$ and certainly the amount of time required to exhaust all possibilities is greatly increased. As an example, certain stochastic adjacency matrices have only one eigenvalue of multiplicity one. In many of these cases, the corresponding eigenvector components are all identical. In this, as well as in other less severe cases, the above described method of finding a permutation of $A$ into $B$ is not practical.

For such graphs a more sophisticated, as well as time consuming, approach is required. Again referring to the relation $U E=P V$, it is useful to examine the case when an eigenvalue has multiplicity two. In other words, assume that $d_{j j}=d_{k k}$ for $k=j, j+1$ but $d_{j j} \neq d_{k k}$ for all other $k$. Then we know that

$$
\left(\begin{array}{cc}
u_{1 j} & u_{1 j+1} \\
u_{2 j} & u_{2 j+1} \\
\cdot & \cdot \\
\cdot & \cdot \\
\cdot & \cdot \\
u_{n j} & u_{n j+1}
\end{array}\right) \quad\left(\begin{array}{rr}
a & -b \\
b & a
\end{array}\right)=P \quad\left(\begin{array}{cc}
v_{1 j} & v_{1 j+1} \\
v_{2 j} & v_{2 j+1} \\
\cdot & \cdot \\
\cdot & \cdot \\
\cdot & \cdot \\
v_{n j} & v_{n j+1}
\end{array}\right)
$$

or that

$$
\left(\begin{array}{cc}
u_{1 j} & u_{1 j+1} \\
u_{2 j} & u_{2 j+1} \\
\cdot & \cdot \\
\cdot & \cdot \\
\cdot & \cdot \\
u_{n j} & u_{n j+1}
\end{array}\right) \quad\left(\begin{array}{cc}
a & b \\
b & -a
\end{array}\right)=P \quad\left(\begin{array}{cc}
v_{1 j} & v_{1 j+1} \\
v_{2 j} & v_{2 j+1} \\
\cdot & \cdot \\
\cdot & \cdot \\
\cdot & \cdot \\
v_{n j} & v_{n j+1}
\end{array}\right)
$$

In each case, there are $n$ possible values for $a$. Selecting $i$ such that either $u_{i j} \neq 0$ or $u_{i j+1} \neq 0$ and assuming that there is a permutation of $A$ into $B$ which takes the $i$ th node of $A$ into the $k$ th node of $B$, we have

$$
\begin{aligned}
u_{i j} a+u_{i j+1} b & =v_{k j} \\
-u_{i j} b+u_{i j+1} a & =v_{k j+1} \\
\text { or } & \\
u_{i j} a+u_{i j+1} b & =v_{k j} \\
u_{i j} b-u_{i j+1} a & =v_{k j+1}
\end{aligned}
$$

which yields

$$
\begin{array}{ll}
\left(\begin{array}{ll}
u_{i j} & u_{i j+1} \\
u_{i j+1} & -u_{i j}
\end{array}\right) & \left(\begin{array}{l}
a \\
b
\end{array}\right)=\left(\begin{array}{c}
v_{k j} \\
v_{k j+1}
\end{array}\right) \\
\left(\begin{array}{cc}
u_{i j} & u_{i j+1} \\
-u_{i j+1} & u_{i j}
\end{array}\right) & \left(\begin{array}{l}
a \\
b
\end{array}\right)=\left(\begin{array}{c}
v_{k j} \\
v_{k j+1}
\end{array}\right) .
\end{array}
$$

Solving for $a$ and $b$ yields:

$$
\begin{aligned}
& \boldsymbol{a}=\frac{u_{i j} v_{k j}+u_{i j+1} v_{k j+1}}{u_{i j}{ }^{2}+u_{i j+1}{ }^{2}}, \\
& b=\frac{-u_{i j} v_{k j+1}+u_{i j+1} v_{k j}}{u_{i j}{ }^{2}+u_{i j+1}{ }^{2}}
\end{aligned}
$$




$$
\begin{gathered}
\text { or } \\
a=\frac{u_{i j} v_{k j}-u_{i j+1} v_{k j+1}}{u_{i j}{ }^{2}+u_{i j+1}{ }^{2}}, \\
b=\frac{u_{i j} v_{k j+1}+u_{i j+1} v_{k j}}{u_{i j}{ }^{2}+u_{i j+1}{ }^{2}} .
\end{gathered}
$$

Note that $a^{2}+b^{2}=1$ so that $|a| \leq 1$. Thus the permutations $P$ are limited to those that satisfy

$$
a\left(\begin{array}{c}
u_{1 j} \\
u_{2 j} \\
\cdot \\
\cdot \\
\cdot \\
u_{n j}
\end{array}\right)+b\left(\begin{array}{c}
u_{1 j+1} \\
u_{2 j+1} \\
\cdot \\
\cdot \\
\cdot \\
u_{n j+1}
\end{array}\right)=P\left(\begin{array}{c}
v_{1 j} \\
v_{2 j} \\
\cdot \\
\cdot \\
\cdot \\
v_{n j}
\end{array}\right)
$$

for any of the $2 n$ pairs of $(a, b)$, two pairs corresponding to each value of $k$. For each $(a, b)$, the problem then reduces to the previously examined case of eigenvalues of multiplicity one. The only difference is that the process must be repeated $2 n$ times before all possible permutations have been checked.

SUBROUTINE OPTEIG selects an optimal eigenvector, one that has as few multiple components as possible, and takes $0\left(n^{3}\right)$ time. If the selected eigenvector corresponds to an eigenvalue of multiplicity one, SUBROUTINE SINGLE is called upon. This subroutine is $0\left(n^{3}\right)$ but the leading coefficient can be very large if there are large numbers of multiple eigenvector components. SUBROUTINE DOUBLE calls SUBROUTINE SINGLE at most $2 n$ times and thus is $0\left(n^{4}\right)$ with the possibility of a very large leading coefficient.

Due to the complex nature of the relation $U E=P V$ for blocks of $E$ of dimension greater than two, little progress was made in obtaining meaningful data from the eigenvectors corresponding to eigenvalues of multiplicity greater than two.

Should neither the eigenvectors corresponding to eigenvalues of multiplicity one nor those of multiplicity two sufficiently restrict the number of permutations possible, still other algebraic approaches can be employed.

One such approach is the examination of the spectra of the $n$ subgraphs of order $n-1$ of the original graph. An obvious necessary condition for isomorphism is that the two graphs generate the same sets of spectra. Further there is the possibility that in a given set of spectra, many of them will be unique, thus creating the possibility of generating and testing all possible permutations in a small amount of time. Distinguishing node duplicates again helps to reduce the maximum number of permutations possible. Experience with a limited number of large stochastic matrices has shown, however, that this procedure is far more effective as a nonisomorphism test than as one that attempts to generate and test all possible permutations. This procedure is contained in SUBROUTINE SUBVAL and takes $0\left(n^{4}\right)$ time.

Carrying the eigenvector analysis further all possible permutations can be derived through examination of eigenvectors of subgraphs of the original graph. This method has proved to be one of the most successful in distinguishing very difficult large, stochastic graphs. For simplicity and speed, all submatrices of order $n-1$ are searched for the optimum or a sufficiently satisfactory eigenvector corresponding to an eigenvalue of multiplicity one. This eigenvector is then compared with the corresponding eigenvector generated from each of the subgraphs of the second graph that has a spectrum matching the spectrum of the subgraph which generated the optimal eigenvector. This procedure is executed in SUBROUTINE SUBVEC. The order is $0\left(n^{4}\right)$ as SUBROUTINE SINGLE can be called a maximum of $n$ times. This approach tends to be more time consuming than the others mentioned since it could require the generation of $n$ eigenvector matrices.

In a similar fashion, one could examine the eigenvectors of subgraphs corresponding to eigenvalues of multiplicity two. Another possible approach would be to examine the $n^{2}$ spectra generated by sequentially generating all possible subgraphs of order $n-2$. These and other possible procedures are $0\left(n^{5}\right)$ or worse and very time consuming. It does not appear that the trade off of speed for effectiveness dictates inclusion of such unwieldly approaches in the algorithm.

\section{Computer Implementation}

The algorithm was organized into fourteen subroutines and coded in FORTRAN V for use with the UNIVAC 1108 computer. SUBROUTINE GISOM serves as the coordinating subroutine and is the 
only subroutine that need be referenced by a main program. Each subroutine listing is fully commented, indicating values of variables on input, output and during the life of the subroutine.

All eigenvalues and eigenvectors were calculated using the EISPACK software described in [9]. Reference to [9] should be made for a detailed explanation of the function, running time, error messages and accuracy of the EISPACK subroutines. Throughout the program two numbers, $A$ and $B$ are considered identical if ||$A|-| B||<$ MACHP * $(1+|A|)$. The precision constant, MACHP, is determined and set by the user in the call to GISOM. For use with the EISPACK software on the UNIVAC 1108 , a value of MACHP $=0.0003$ was found to be satisfactory.

Another user option in the call to GISOM command sets a limit on the number of permutations that may be tested for a given pair of graphs. Generally, this value, MAXT, can be set to a very large number, say 5000 , since very little time is expended on each test. MAXT is of greatest use when it is desired to sequentially test several pairs of very large matrices without spending too much time on any one pair.

Time rather than storage conservation was emphasized. The subroutines utilize five $n \times n$ arrays and several single dimension $0(n)$ arrays, all of which are passed as part of the subroutine call statements. There are no common blocks and no input-output statements in the subroutine as all pertinent data is returned through the CALL GISOM command in the main program. The STATUS and ERR variables serve as the key to what happened when the two graphs were tested for isomorphism. The other variables contain a variety of data whose meaning depends on the value of ERR and STATUS. This data can often be quite useful in determining exactly why two graphs are not isomorphic. The interpretation of ERR and STATUS is given with the commentary of each subroutine. A list of the program follows. 


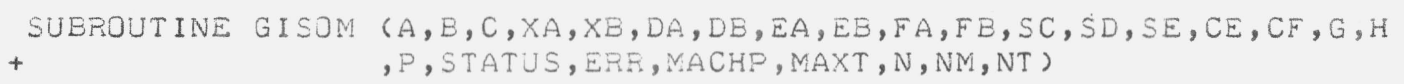

C

C

C

C

C

C

c

C

C

C

C

C

C

C

C

C

C

C

C

C

C

C

C

C

C

C

C

C

C COMPARE the NODE VALENCES AND update the CORRESPONDING NOdE LAEELS.

ON INPUT:

A AND B CONTAIN THE 0,1 FORM OF THE ADJACENCY MATRICES OF THE TWO GRAPHS TO BE COMPARED. THE DIAGONAL ELEMENTS CONTAIN LARELS WHICH MAY RANGE IN VALUE FROM O TO 99.

MACHP IS THE PRECISION WITHIN WHICH EQUALITY IS TO BE TESTED. A VALUE OF .0003 IS SUGGESTED WHEN THE PROGRAM IS RUN ON A MACHINE COMPAFAELE TO THE UNIVAC 1108 AND WITH SOFTWAFE EQUIVALENT TO EISPACK IN ACCURACY.

MAXT IS APPROXIMATELY THE MAXIMUM NUMEER OF PERMUTATIONS THAT MAY SE TESTED. EXCEPT IN CASES OF SEVERE TIME RESTRICTIONS, A VALUE OF 5000 IS SUGGESTED.

$N$ IS THE ORDER OF THE GRAPHS TO BE COMPARED.

NM IS THE DIMENSION OF MOST OF THE ARRAYS.

$N T=2 * N M$ AND IS THE DIMENSION OF CE AND CF.

ON RETURN:

A AND B ARE POSSIBLY DESTROYED.

P CONTAINS A PERMUTATION SUCH THAT $A(I, J)=B(P(I), P(J)$ ) FOR ALL $I, J$ SHOULD SUCH A PERMUTATION BE FOUND TO EXIST.

STATUS RANGES IN VALUE FROM 1 TO 10 AND RECORDS THE POINT IN GISOM WHERE THE ALGORITHM TERMINATED. FOR EXAMPLE, A VALUE OF STATUS $=3$ MEANS THAT THE ALGORITHM TERMINATED FOLLOWING THE NODE VALENCE CHECK WHICH IMPLIES THAT THE NODE VALENCES OF THE TWO GRAPHS DIFFERED AND THUS THAT THE TWO GRAPHS ARE NOT ISOMORPHIC.

ERR CONTAINS INFORMATION PERTAINING TO THE REASON FOR THE TERMINATION OF THE ALGORITHM. AN EXPLANATION OF ITS MEANING CAN BE FOUND WITH THE COMMENTS IN THE SUBROUTINE THAT WAS LAST CALLED BY GISOM. FOA EXAMPLE, A STATUS VALUE OF 7 COMEINED WITH AN ERR OF O IMPLIES THAT A PERMUTATION WAS FOUND THAT RELATES A AND B THEOUGH USE OF AN EIGENUECTOR CORRESPONDING TO AN EIGENUALUE OF MULTIPLICITY ONE.

MACHP, MAXT, $N$, NM, AND NT ARE UNCHANGED.

ALL OTHER VARIABLES ARE CLASSIFIED AS WORKING VARIABLES. SUCH VAFIAELES MAY CONTAIN RELEVANT INFORMATION DEPENDING ON THE VALUES OF STATUS AND ERR.

\footnotetext{
INTEGER $N, N M, N T, E R R, M A X T, G(N M), H(N M), P(N M)$, STATUS, JA

REAL A(NM,NM), E(NM,NM), C(NM,NM), XA(NM,NM), XB(NM,NM), DA(NM), DB(NM), $+\quad E A(N M), E B(N M), F A(N M), F B(N M), S C(N M), S D(N M), S E(N M), C E(N T), M A C H P$ $+\quad, C F(N T)$
}

$E R R=0$

STATUS $=1$

IF (N.GT.NM) RETURN

COMPARE THE NODE LABELS OF THE TWO GRAPHS.

STATUS $=2$

CALL LABEL ( $A, B, D A, D B, S C, E P R, N, N M)$

IF (ERR.GT.0) RETURN

THIS SUBROUTINE IS THE CONTROL SUBROUTINE FOR THE ALGORITHM. 
C

STATUS $=3$

CALL VALENC ( $A, B, D A, D B, S C, E P R, N, N M)$

IF (ERR,GT,O) RETURN

C

C

C

10 STATUS $=$ STATUS +1

CALL DUPLIC ( $A, B, D A, D B, S C, S D, E R R, S T A T U S, N, N M)$

IF (ERF.GT.0) RETURN

IF (STATUS.EQ.4) GO TO 10

$\mathrm{C}$

$\mathrm{C}$

C

CONUERT THE 0,1 FORM OF THE ADJACENCY MATRIX TO THE $1, X$ FORM.

CALL PREPAR ( $A, E, D A, D \bar{B}, N, N M)$

COMPUTE AND COMPARE thE SPECTRA of the tWo ADJACENCy MATRICES.

STATUS $=6$

CALL SPECTR ( $A, B, X A, X B, E A, E B, S C, G, E R R, M A C H P, N, N M)$

IF (ERR.NE. O) RETURN

LOCATE A SUITAELE OR OPTIMAL EIGENVECTOR.

CALL OPTEIG (XB, DB, G,ERR, MACHP, JA, N, NM)

GO TO $(20,30,50)$, EPR

ATTEMPT TO FIND A PERMUTATION THAT RELATES A AND B THROUGH USE DF AN EIGENVECTOR THAT CORRESPONDS TO AN EIGENUALUE OF MULTIPLICITY ONE.

$20 \quad$ STATUS $=7$

CALL SINGLE ( $A, E, X A, X B, F A, F E, H, P, E R R, M A C H P, M A X T, J A, N, N M)$

GO TO 40

C

$\mathrm{C}$

ATTEMPT TO FIND A PERMUTATION THAT RELATES A AND E THROUGH USE OF AN EIGENUECTOR THAT CORRESPONDS TO AN EIGENVALUE OF MULTIPLICITY TWO.

C

30 STATUS $=8$

CALL DOUBLE ( $A, B, C, X A, X B, C E, C F, F A, F B, H, P, E R R, M A X T$, MACHP, JA, N, NM, NT

C

40 IF (ERR.NE.4) RETURN

COMPUTE AND COMPARE THE SPECTRA OF THE N ORDER N-1 SUBGRAPHS OF THE

ORIGINAL GRAPHS.

C

$50 \quad$ STATUS $=9$

CALL SUBVAL ( $A, B, C, X A, S C, S D, S E, H, P, E R R, M A C H P, M A X T, N, N M)$

IF (ERR・NE・ 0 .AND.ERR.NE.5+N) RETURN

ATTEMPT TO FIND A PERMUTATION THAT RELATES A AND B THROUGH USE OF AN EIGENVECTOR THAT CORRESPONDS TO AN EIGENVALUE JF MULTIPLICITY ONE IN A SUBGRAPH OF ORDER $\mathrm{N}-1$.

STATUS $=10$

CALL SUBVEC ( $A, B, C, X A, X B, D A, D B, E A, E B, F A, F B, S C, S D, S E, G, H, P, E R R$,

C

$+$ MACHP, MAXT, N, NM)

RETURN

END 
SUBROUTINE LABEL ( $A, B, D A, D B, S C, E R R, N, N M)$

C THIS SUBROUTINE RECORDS AND COMPARES THE INITIAL LABELS OF THE NODES

C OF THE TWO GRAPHS TO BE COMPARED.

C

C ON INPUT:

C A AND B CONTAIN THE TWO ADJACENCY MATRICES TO BE COMPARED.

C N IS THE ORDER OF THE GRAPHS.

C NM IS THE DIMENSION OF THE ARRAYS.

C

A AND B ARE UNCHANGED.

DA AND DB CONTAIN THE DIAGONAL ELEMENTS -LABELS- OF A AND B.

ERR = 0 IF DA AND DE ARE ISOMORPHIC. OTHERWISE ERR IS THE INDEX

OF THE ELEMENT OF DA WHICH CANNOT BE MATCHED IN DB.

$N$ AND NM ARE UNCHANGED.

C

WORKING ARRAYS: $S C$

INTEGER N, NM, ERR, I

REAL $A(N M, N M), B(N M, N M), D A(N M), D B(N M), S C(N M)$

C

C RECORD THE LABELS.

C

DO $10 \quad I=1, N$

$D A(I)=A(I, I)$

$D B(I)=B(I, I)$

10 CONT INUE

C

C COMPARE THE LABELS.

$C$ NOTE THAT SINCE THE LABELS ARE INTEGERS, THE MACHINE PRECISION

C CONSTANT IS ZERO.

C

CALL COMP ( DA, DB, SC,ERR, O, N,NM)

C

RETURN

END 


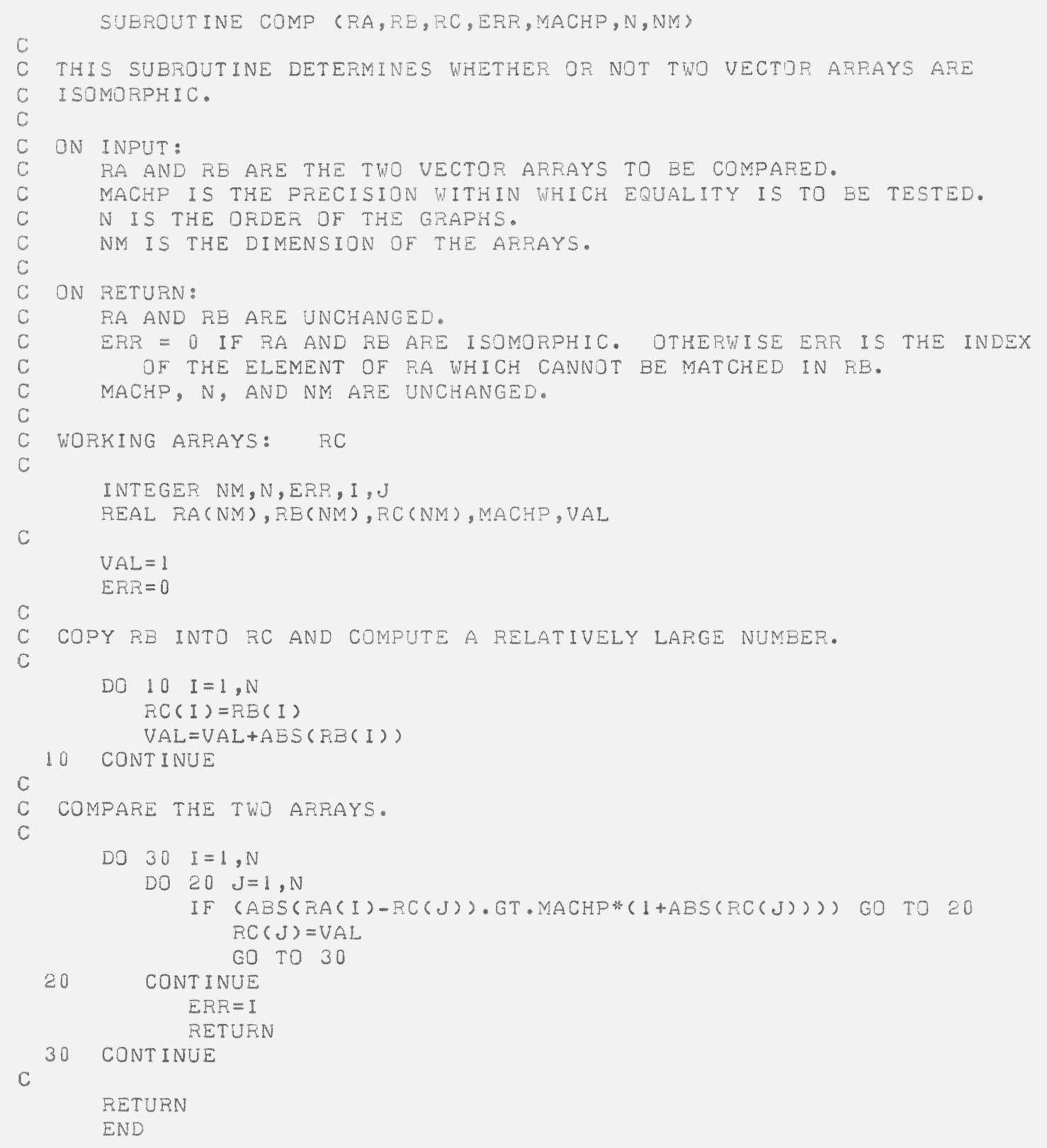


SUBROUT INE VALENC ( $A, B, D A, D B, S C, E R R, N, N M_{i}$ )

C

C

C

C

C

C

C

C

C

C

C

C

C

C

C

C

C

C

C

C MAKE ROOM FOR NEW INFORMATION.

C

C

C

C

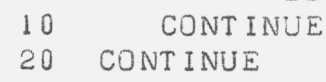

C 
SUBROUTINE DUPLIC ( $A, B, D A, D B, S C, S D, E R R, Q, N, N M)$

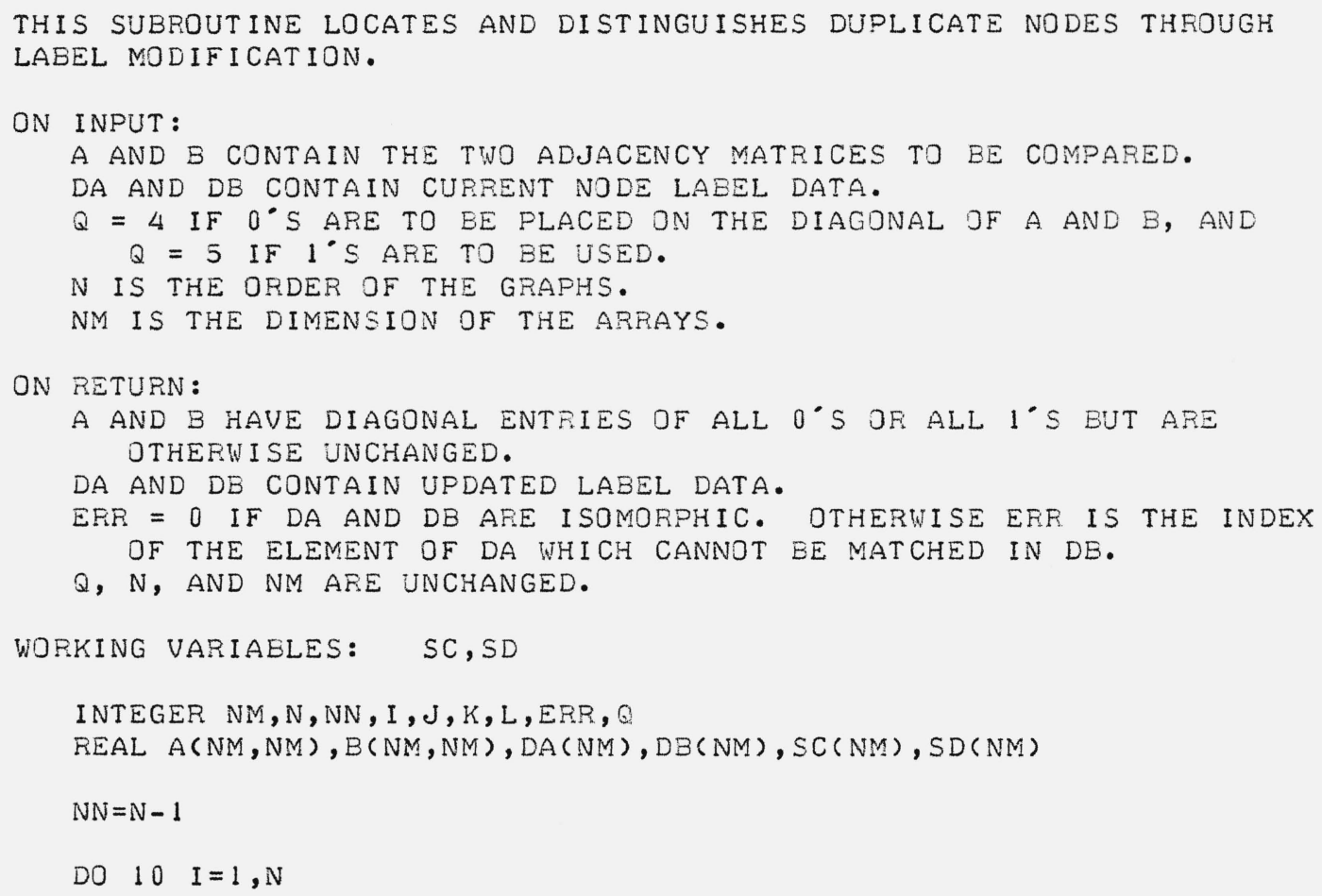




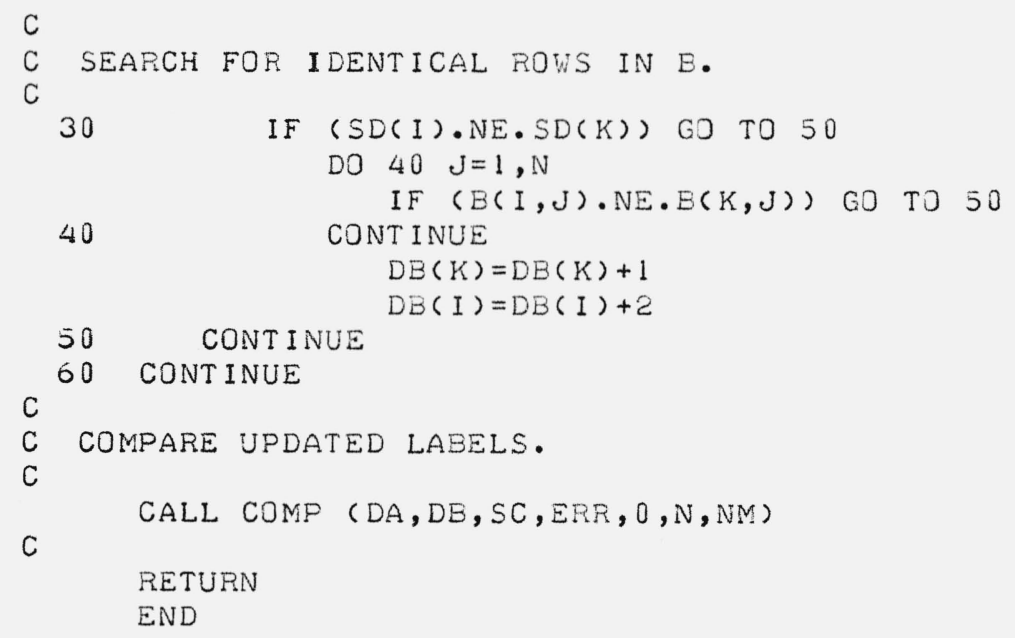


SUBROUTINE PREPAR ( $A, B, D A, D B, N, N M)$

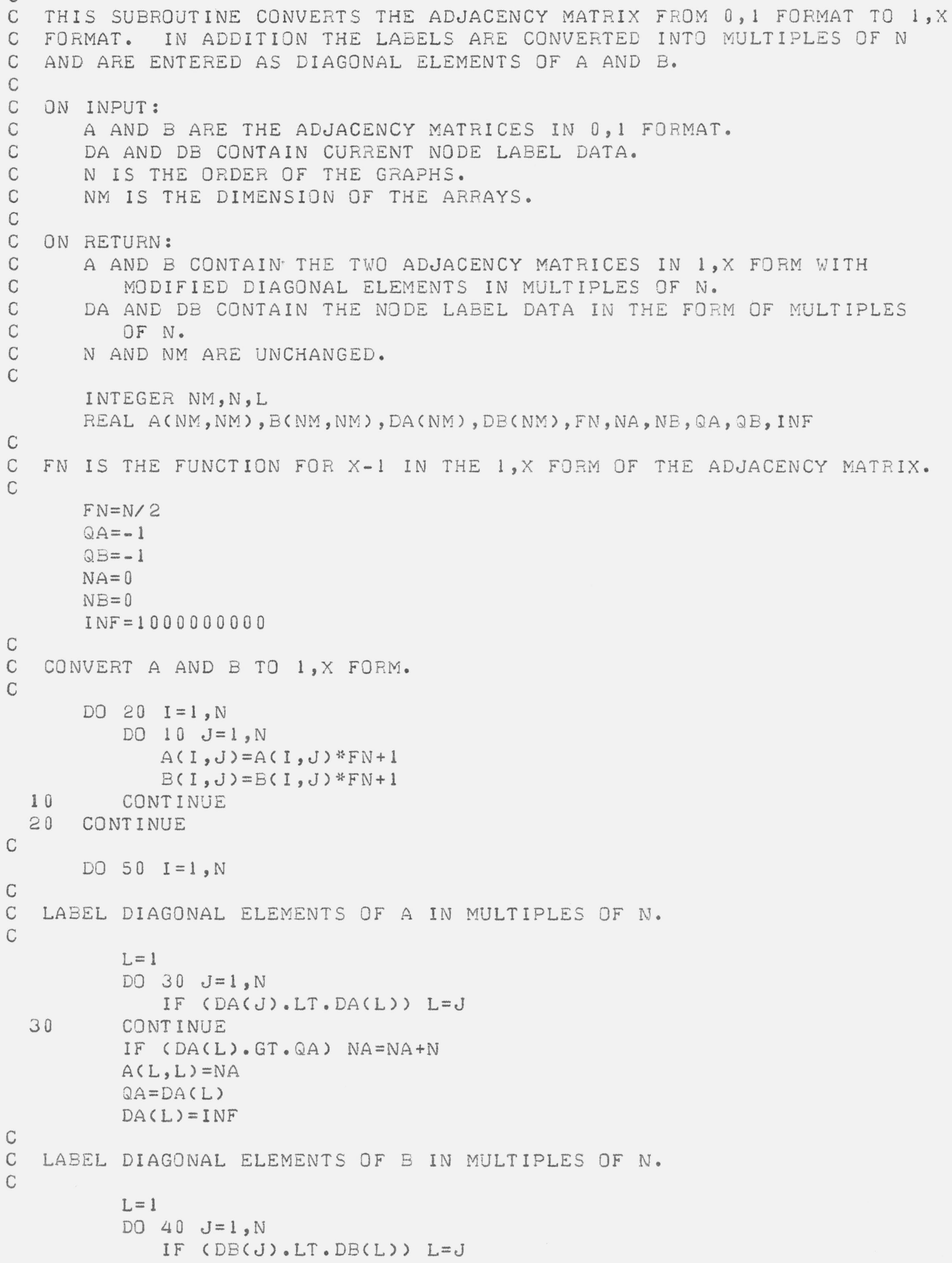




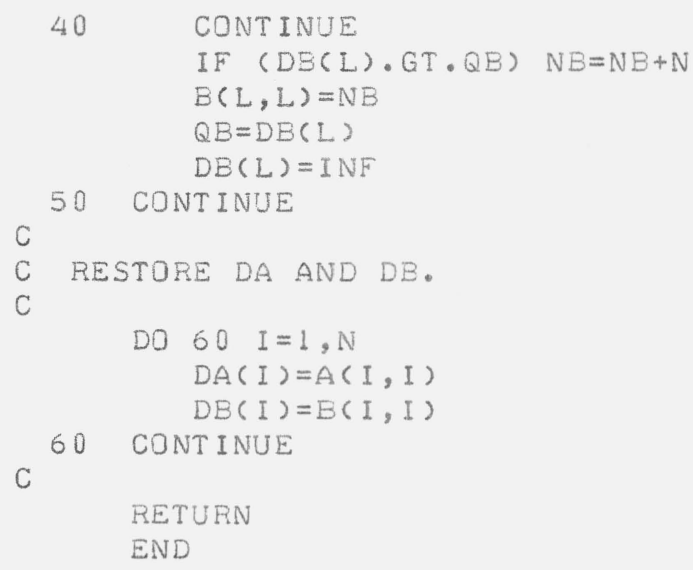




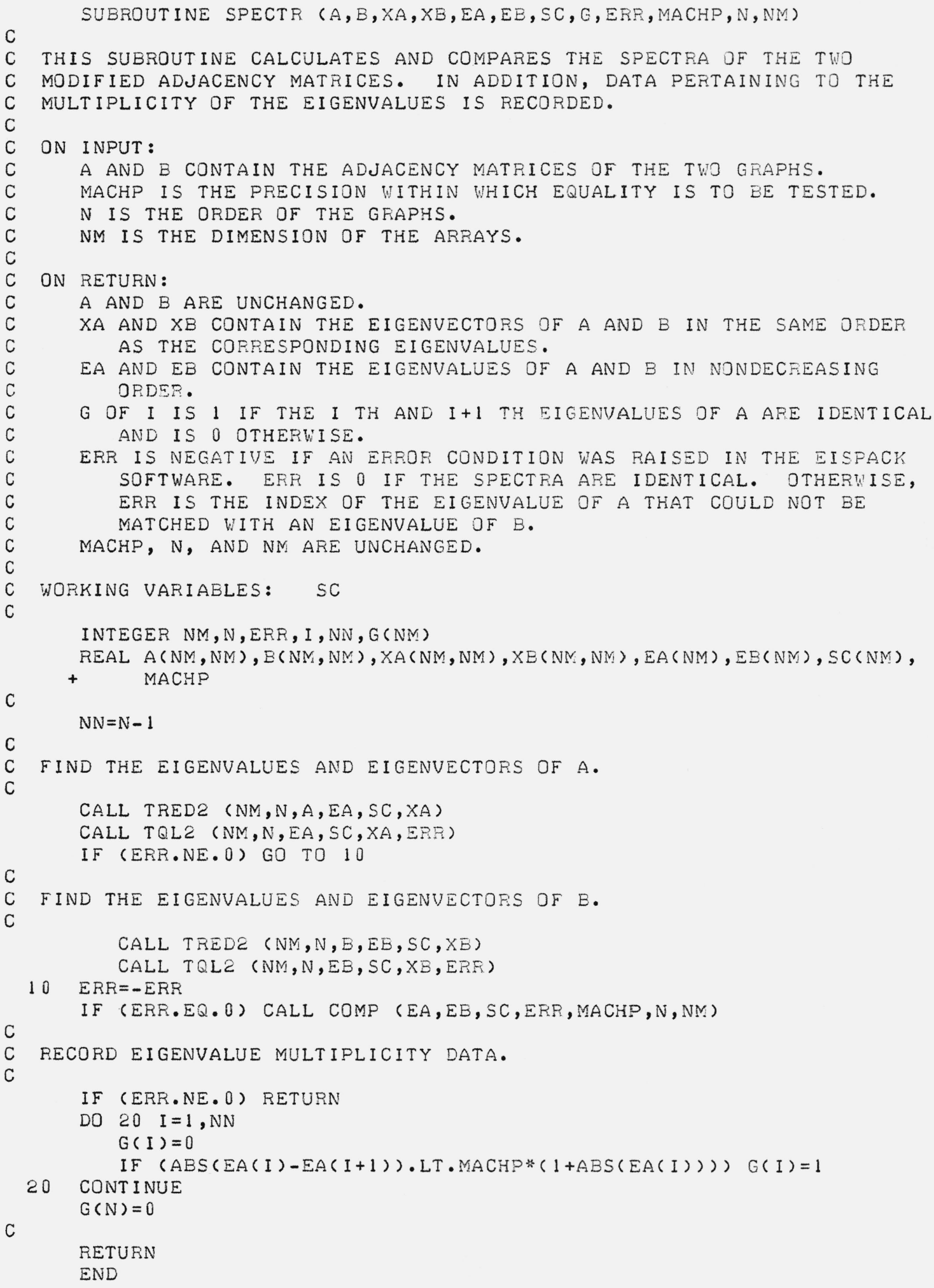


SUBROUTINE OPTEIG (XB, DB, G, ERR, MACHP, JA, N, NM)

THIS SUBROUTINE SELECTS AN OPTINAL EIGENVECTOR FOR USE IN GENERATING A SERIES OF PERMUTATIONS.

ON INPUT:

$X B$ IS THE EIGENUECTOR MATRIX DF B.

DB CONTAINS THE DIAGONAL ELEMENTS OF B.

G CONTAINS EIGENVALUE MULTIPLICITY INFORMATION.

MACHP IS THE PRECISION WITHIN WHICH EQUALITY IS TO BE TESTED.

$N$ IS THE ORDER OF THE GRAPHS.

NM IS THE DIMENSION JF THE ARRAYS.

ON RETURN :

$X B$ IS ESSENTIALLY UNCHANGED. THE POSSIBILITY EXISTS THAT ANY TWO EIGENUECTORS CORRESPONDING TO THE SAME EIGENVALUE CJULD BE INTERCHANGED.

DB AND G ARE UNCHANGED.

ERR = 1 IF THE EIGENVECTOR SELECTED CORRESPONDS TO AN EIGENVALUE OF MULTIPLICITY 1. ERR $=2$ IF THE CORRESPONDING EIGENVALUE HAS MULTIPLICITY 2. ERR=3 IF NO SUITAELE EIGENVECTOR COULD BE FOUND.

MACHP IS UNCHANGED.

JA IS THE COLUMN INDEX OF THE OPTIMAL EIGENVECTOR, IF ONE EXISTS. $N$ AND NM ARE UNCHANGED.

INTEGER NM, N, I, J,PN, LT, PX, ERR, JA, LI, LM, L, NN, G (NM)

REAL XB(NM, NM), DB(NM), MACHP

C

$\mathrm{NN}=\mathrm{N}-1$

$E R R=3$

$P N=1000$

ALL EIGENUECTORS WITH THREE OR MORE IDENTICAL COMDONENTS OR THAT

CORRESPOND TO EIGENVALUES OF MULTIPLICITY THREE OR MORE ARE

ELIMINATED FROM CONSIDERATION. EIGENVECTORS THAT CORRESPOND TO

EIGENVALUES OF MULTIPLICITY ONE ARE CONSIDERED PREFERENTIALLY TO

THOSE WHICH HAVE MULTIPLICITY TWO. EIGENVECTORS WHICH HAVE FEW PAIRS

OF IDENTICAL CDMPONENTS ARE FAVORED OVER THOSE WITH MANY SUCH PAIRS.

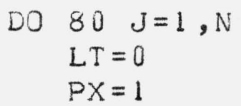

C

C CHECK FOR MULTIPLICITY OF ASSOCIATED EIGENUALUE.

$\mathrm{C}$

IF (J.EQ.1) GO TO 20

IF $(G(J-1) \cdot E Q \cdot 0)$ GO TD 20

IF $(J \cdot E Q \cdot 2)$ GO TO 10

IF $(G(J-2) \cdot E Q \cdot 1 \cdot)$ GO TO 80

10

IF $(G(J) \cdot E Q \cdot 1)$ GO TO 80

LT $=4$

$\mathrm{PX}=4$

GO TO 30

20 IF $(\mathrm{G}(\mathrm{J}) \cdot \mathrm{EC} \cdot \mathrm{O})$ GO TO 30

IF $(G(J+1) \cdot E Q \cdot 1)$ GO TO 80

LT $=4$

$\mathrm{PX}=2$ 


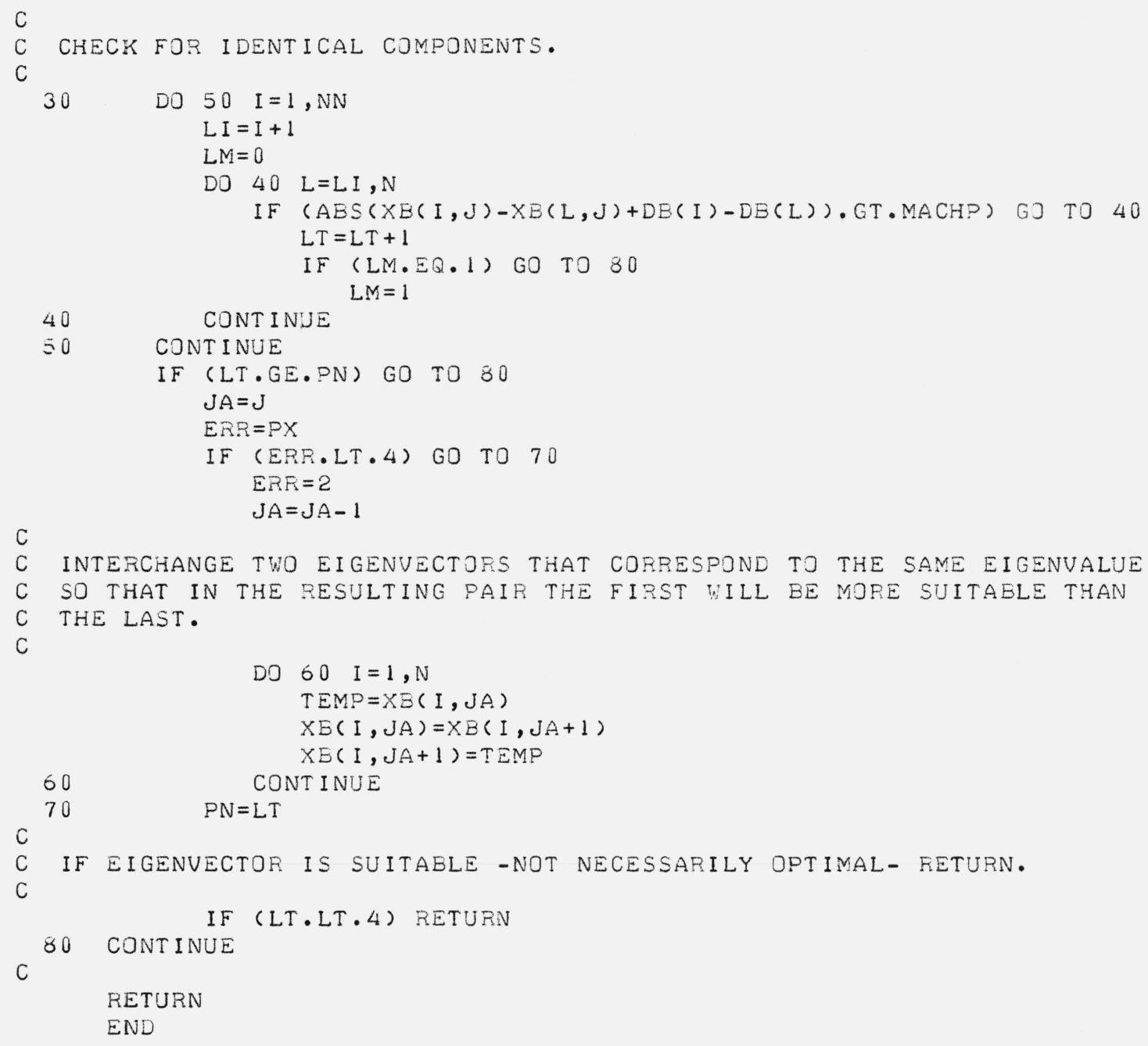


SUBROUT INE SINGLE ( $A, B, X A, X B, F A, F B, H, P, E R R, M A C H P, M A X T, J A, N, N M$ )

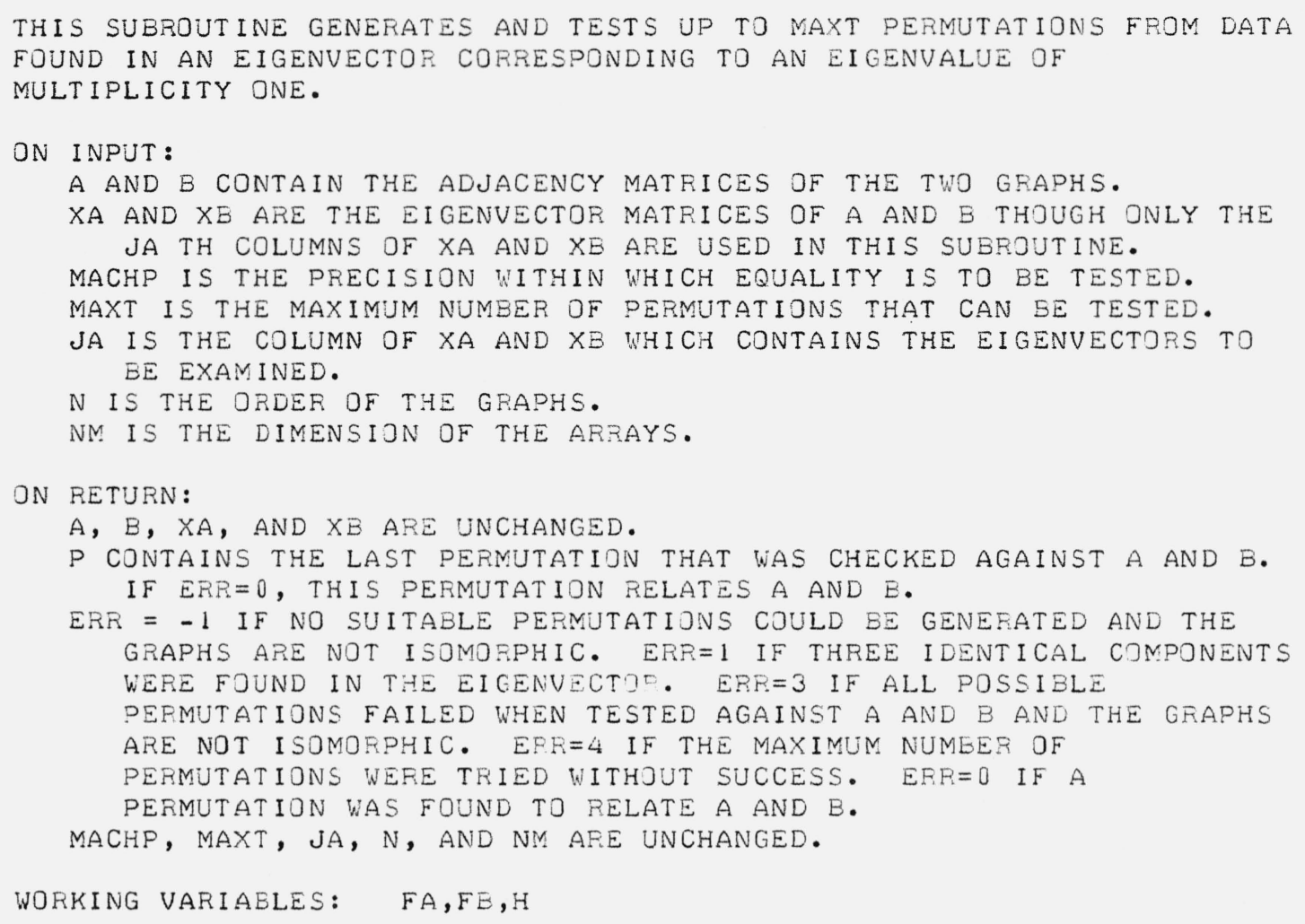




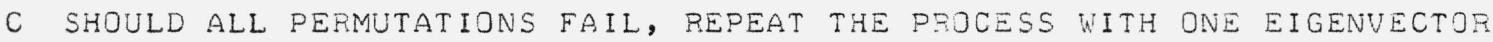

C NEGATED TO INCLUDE ALL POSSIBLE CASES.

$\mathrm{C}$

DO $40 I=1, N$

$F B(I)=B(I, I)-X B(I, J A)$

40 CONT INUE

$M=1$

GO TO 20

c

END 
SUBROUTINE PERM (FA,FB, H, P, ERR, NACHP, LT, N, NM)

C THIS SUBROUTINE gENERATES A SINGLE PERMUTATION EETWEEN THE COMPONENTS C OF TWO VECTORS AND RECORDS THE DATA NECESSARY TO GENERATE ALL OTHER

C POSSIBLE PERMUTATIONS BETWEEN THE COMPONENTS OF THE TWO VECTORS. THE

C VECTORS MUST NOT CONTAIN MORE THAN TWO IDENTICAL COMPONENTS.

C

C

INTEGER NM, N, I, J,L, LT, H(NM), P(NM), ERR

REAL FA(NM), FB(NM), MACHP, INF

FA IS UNCHANGED.

FB IS DESTROYED.

H CONTAINS THE INDICES OF THE PAIRS OF IDENTICAL COMPONENTS OF FA. $P$ CONTAINS A PERMUTATION OF THE COMPONENTS OF FA INTO THOSE OF FB. ERR $=-1$ IF THE TWO VECTORS ARE FOUND TO BE NON-ISOMORPHIC. ERR=1 IF THREE OR MORE COMPONENTS OF FA ARE IDENTICAL. $E R R=0$ OTHERWISE. MACHP IS UNCHANGED. LT IS THE NUMBER OF IDENTICAL PAIPS OF COMPONENTS FOUND IN FA. $N$ AND NM ARE UNCHANGED.

$E R R=1$

$L T=0$

C

I $N F=-10$

DO $70 \quad I=1, N$

$L=-1$

C

FIND ALL COMPONENTS OF FB THAT MATCH THE CURRENT COMPDNENT OF FA.

$$
\begin{aligned}
& \text { DO } 30 \mathrm{~J}=1, \mathrm{~N} \\
& \text { IF }(A B S(F A(I)-F B(J)) \text {. GT MACHP) GO TO } 30
\end{aligned}
$$

$$
P(I)=J
$$

40

$$
\text { IF } \begin{gathered}
\text { (L) } 40,70,50 \\
\text { ERR }=-1 \\
\text { RETURN }
\end{gathered}
$$

C

C

C 50

$\mathrm{LT}=\mathrm{LT}+1$

$H(2 * L T-1)=I$

C

C FIND AND RECORD THE INDEX OF THE SECOND HALF OF THE IDENTICAL PAIR C IN FA. 


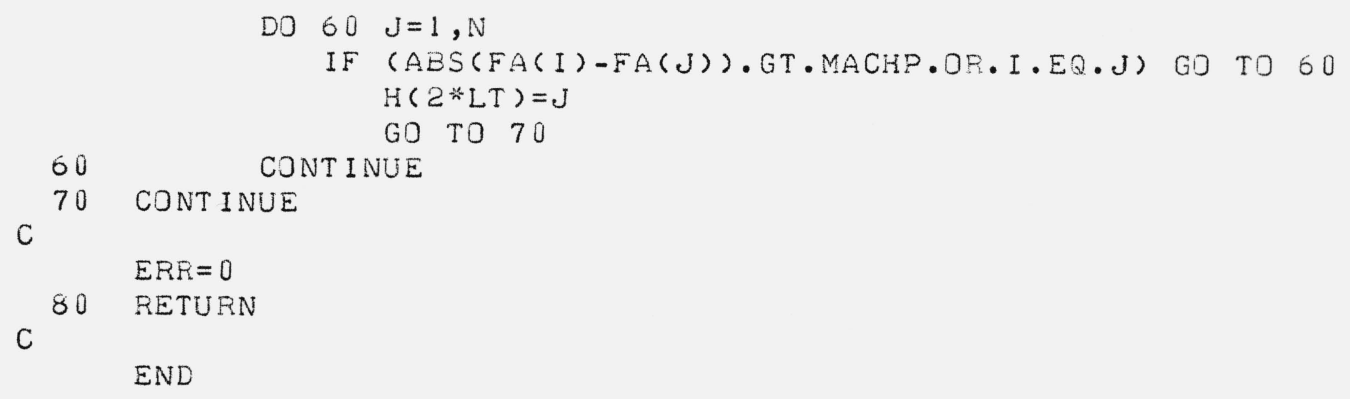


SUBROUTINE TEST ( $A, B, H, P, E R R, M A X T, L T, N, N M)$

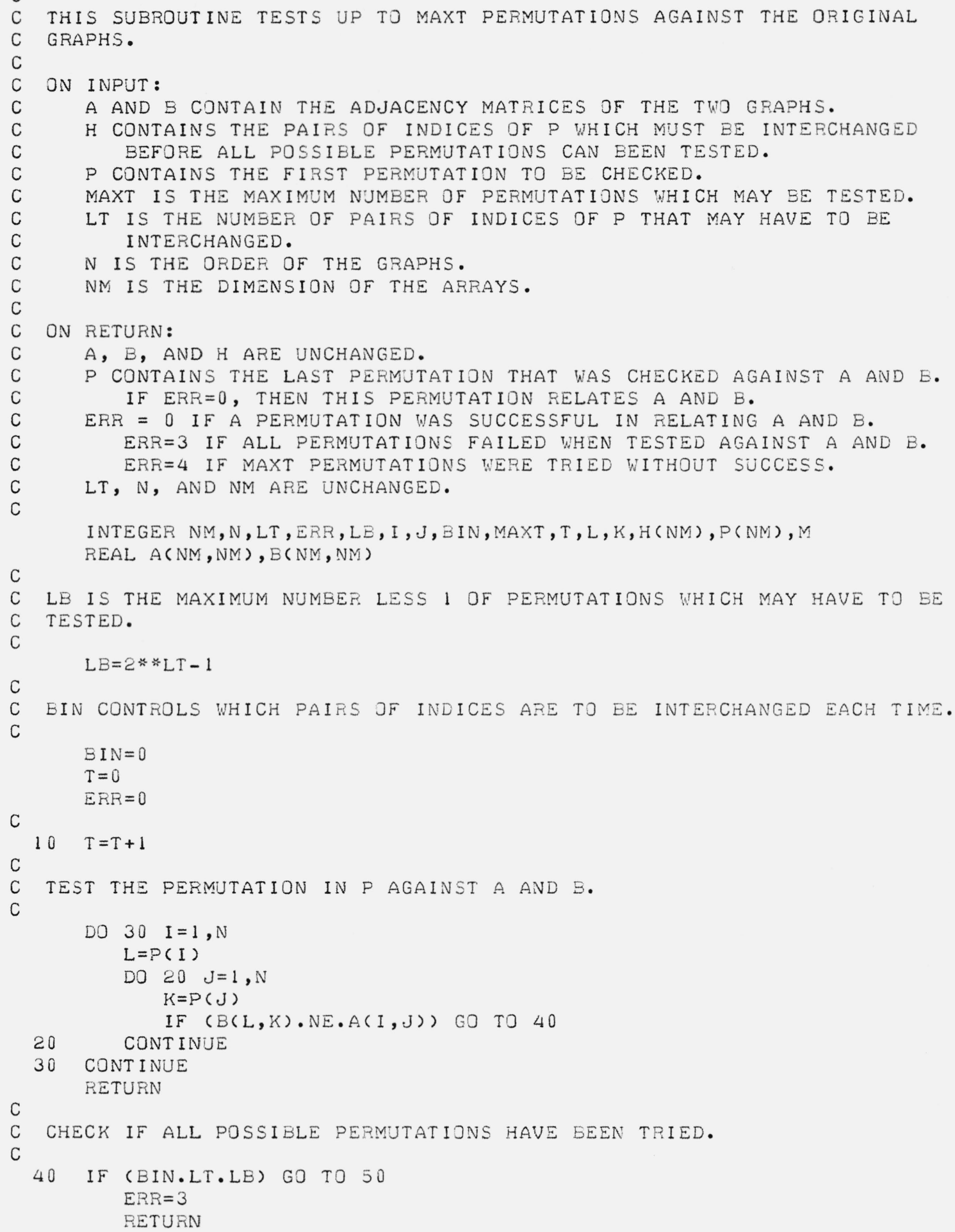




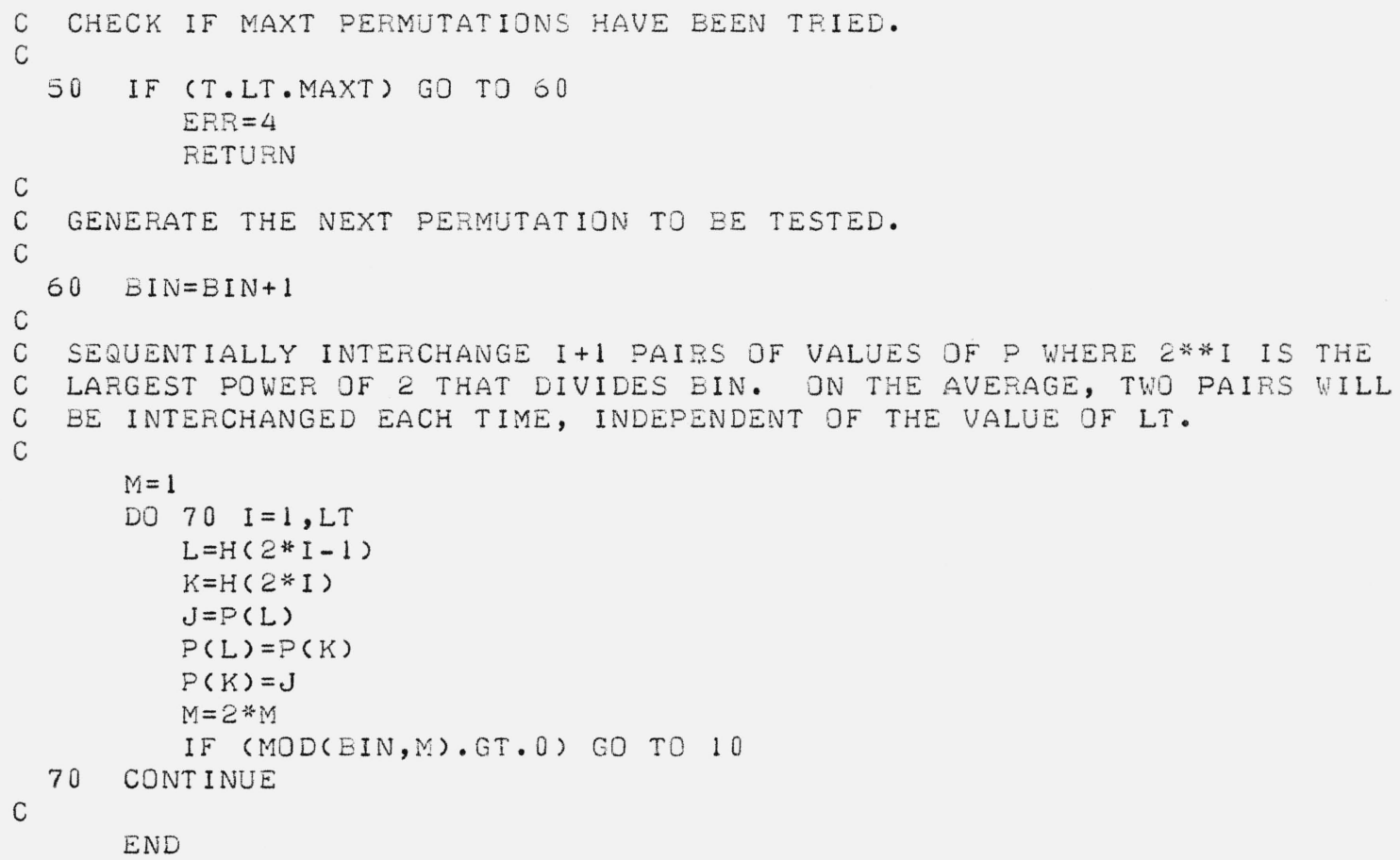




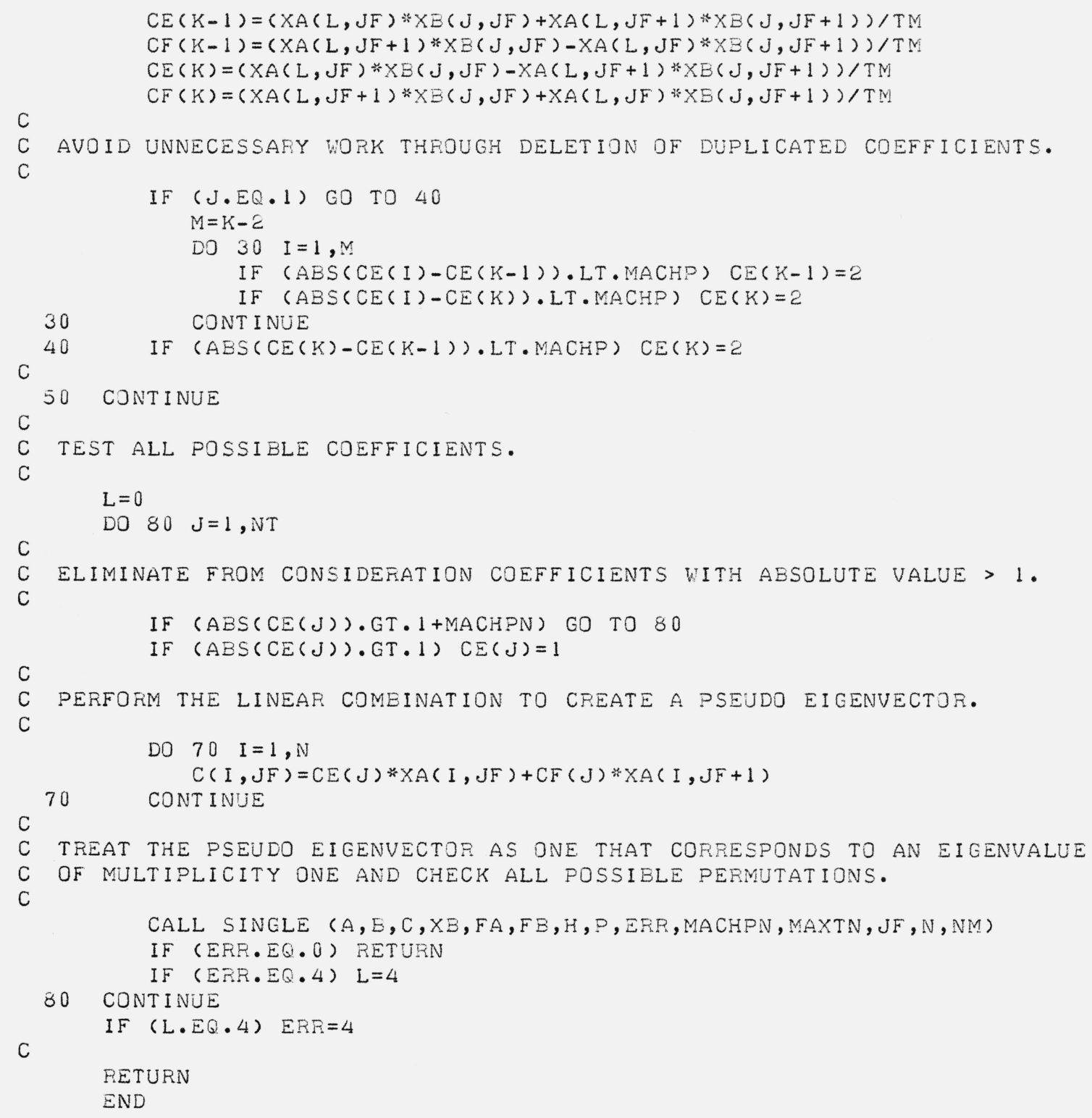


SUBROUTINE SUBUAL ( $A, B, C, X A, S C, S D$, SE, H, P, ERR, MACHP, MAXT, N, NM)

THIS SUBROUTINE GENERATES AND COMPARES THE SPECTPA OF THE ORDER N-1 SUEGRAPHS OF THE TWO ORIGINAL GRAPHS. AN ATTEMPT IS MADE TO GENERATE A PERMUTATION BETWEEN THE TWO GRAPHS BASED ON THIS DATA.

ON INPUT:

A AND E CONTAIN THE ADJACENCY MATRICES JF THE TWO GRAPHS. MACHP IS THE PRECISION WITHIN WHICH EQUALITY IS TO BE TESTED. MAXT IS THE MAXIMUN NUMBER OF PERMUTATIONS THAT COULD BE TRIED IF THE OPTIMAL EIGENVECTOR CORRESPONDED TO AN EIGENUALUE OF MULT IPLICTY ONE. $N$ IS THE OPDER OF THE GRAPHS. NM IS THE DIMENSION OF THE ARRAYS.

ON RETURN :

A AND B ARE UNCHANGED.

C CONTAINS SPECTRA DUPLICATION INFORMATION. THE I TH ROW OF C CONTAINS THE INDECIES OF ALL NODES IN A WHICH WHEN UNIQUELY MARKED PRODUCE SPECTRA IDENTICAL TO THAT PRODUCED WHEN THE I TH NODE OF A WAS UNIQUELY MARKED.

XA CONTAINS THE N SPECTRA GENERATED FROM THE SUBGRAPHS OF A. EACH ROW CONTAINS ONE SPECTRA.

SC OF I IS THE NUMBER OF NODES IN A, INCLUDING I, THAT PRODUCED SPECTRA IDENT ICAL TO THAT OF I.

$P$ CONTAINS A PERMUTATION OF THE SET OF SPECTRA OF SUPGPAPHS OF A INTO THOSE OF B. IF ERP $=\mathrm{N}+1$, THIS IS A PERMUTATION OF A INTO B.

ERR IS NEGATIVE IF AN ERROR OCCURS IN THE EISPACK SOFTWARE. IF THE SETS OF SPECTRA ARE NOT ISOMORPHIC, ERR CONTAINS THE INDEX OF THE NODE IN B WHICH WHEN UNIQUELY MARKED, PRODUCED A SPECTRA THAT COULD NOT BE MATCHED WITH A SPECTRA FROM THE SUBGRAPHS OF A. ERR=0 IF THE SETS OF SPECTRA WERE ISDMORPHIC BUT THREE OR MORE NODES OF A, WHICH WHEN UNIQUELY MARKED, PRODUCED IDENT ICAL SPECTRA. ERR $=N+1$ IF A PERMUTATION RELATING A AND B WAS FOUND. ERR=N+4 IF ALL POSSIBLE PERMUTATIONS FAILED TO RELATE A AND B. ERR $=N+5$ IF MAXT PERMUTATIONS WERE GENERATED AND TESTED WITHOUT SUCCESS.

MACHP, MAXT, N, AND NM ARE UNCHANGED.

WORKING VARIABLES: SD, SE,H

INTEGER NM, N, I, J,K,L,ERR, M, MAXT, LT, H(NM), P(NM)

REAL $A(N M, N M), B(N M, N M), C(N M, N M), X A(N M, N M), S C(N M), S D(N M), S E(N M), F N$, $+\quad$ MACHP

C

C

C

C

C

C

C
FN IS THE FUNCTION FOR $X-1$ IN THE $1, X$ FORM OF THE ADJACENCY MATRIX. $\mathrm{FN}=\mathrm{N} / 2$

GENERATE THE SPECTRA OF ALL ORDER N-1 SUBGRAPHS OF A.

$$
\begin{aligned}
\text { DO } 50 \quad I=1, N \\
P(I)=0
\end{aligned}
$$

COPY A INTO C.

DO $20 \quad K=1, N$ 


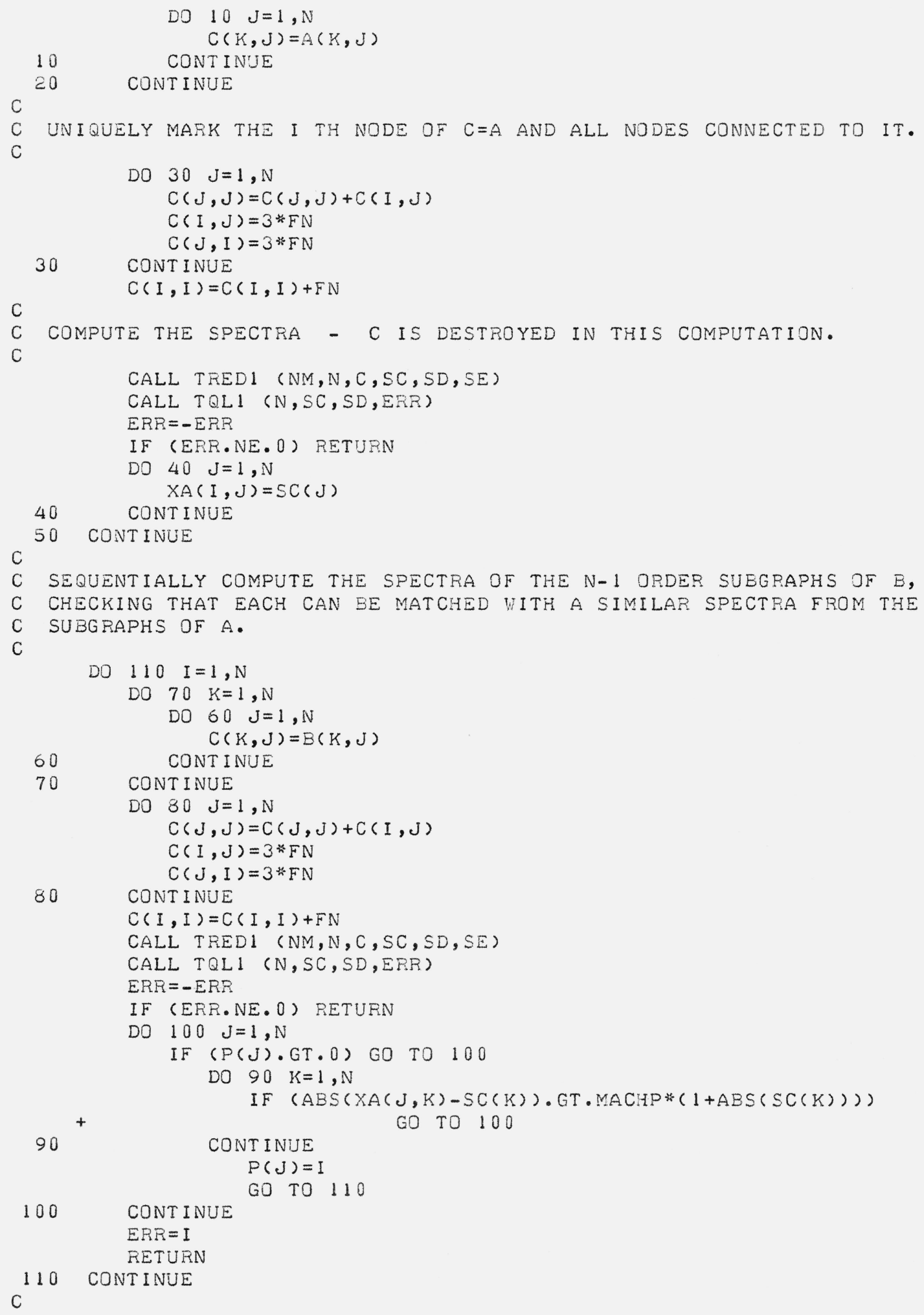




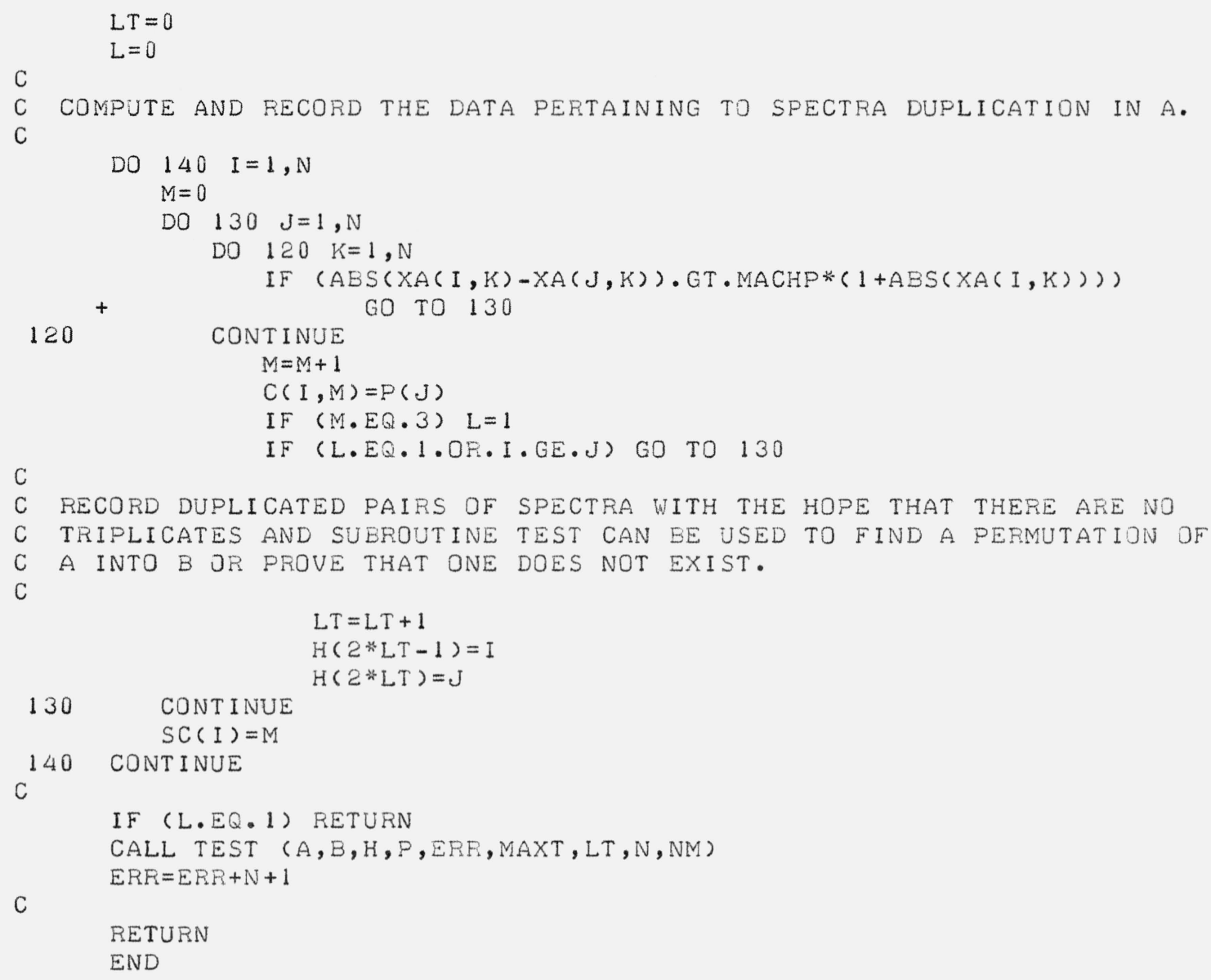


SUBROUT INE SUBVEC ( $A, B, C, X A, X B, D A, D B, E A, E E, F A, F B, S C, S D, S E, G, H, P$, ERR, MACHP, MAXT , N , NM)

THIS SUBROUTINE ATTEMPTS TO GENERATE A PERMUTATION BETWEEN A AND B THROUGH EXAMINATION OF EIGENVECTORS CORRESPONDING TO EIGENVALUES OF MULTIPLICITY ONE OF ORDER $N-1$ SUEGRAPHS OF A AND $B$.

ON INPUT:

A AND B CONTAIN THE ADJACENCY MATRICES OF THE TWO GRAPHS.

C AND SC CONTAIN SPECTRA DUPLICATION INFORMATION.

$P$ CONTAINS A PERMUTATION OF THE SET OF ORDER N-1 SPECTRA OF A INTO THOSE OF B.

MACHP IS THE PRECISION WITHIN WHICH EQUALITY IS TO BE TESTED.

MAXT IS THE MAXIMUM NUMEER OF PERMUTATIONS THAT COULD BE TRIED IF THE OPTIMAL EIGENUECTOR CORRESPONDED TO AN EIGENUALUE OF MULT IPLICTY ONE.

$N$ IS THE ORDER OF THE GRAPHS.

NM IS THE DIMENSION OF THE ARRAYS.

ON RETURN:

A AND B ARE. UNCHANGED.

C AND SC ARE DESTROYED.

P CONTAINS A PERMUTATION OF THE COMPONENTS OF AN EIGENVECTOR OF A SUBGRAPH OF A INTO AN EIGENUECTOR OF A SUEGRAPH OF B. IF ERR $=0$ THEN THE PERMUTATION RELATES A AND B.

$E R R=0$ IF A PERMUTATION OF A INTO B WAS FOUND. ERR=1 IF ALL POSSIBLE PERMUTATIONS FAILED TO RELATE A AND B. ERR=2 IF ALL PERMUTATIONS CHECKED FAILED BUT NOT ALL POSSIBLE PERMUTATIONS WERE TESTED DUE TO THE RESTRICTIONS IMPOSED BY MAXT. ERR=3 IF ALL EIGENUECTORS CORRESPONDING TO EIGENVALUES OF MULTIPLICITY ONE HAD THREE OR MORE IDENTICAL COMPONENTS. ERR IS NEGATIVE IF AN ERROR CONDITION WAS RAISED IN THE EISPACK SOFTWARE.

MACHP, MAXT, N, AND NM ARE UNCHANGED.

WORKING VARIABLES: $\quad \mathrm{XA}, \mathrm{XB}, \mathrm{DA}, \mathrm{DB}, \mathrm{EA}, \mathrm{EB}, \mathrm{FA}, \mathrm{FB}, \mathrm{SD}, \mathrm{SE}, \mathrm{G}, \mathrm{H}$

INTEGER NM, N, MAXT, ERR, I, J, K, L, M, LT, LM, PN, JA, G(NM), H (NM), P(NM), NN

REAL $A(N M, N M), B(N M, N M), C(N M, N M), X A(N M, N M), X B(N M, N M), D A(N M), D B(N M)$,

$+$

$+$ $E A(N M), E B(N M), F A(N M), F B(N M), S C(N M), S D(N M), S E(N M), M A C H P, M A C H P D$ , EIGVAL, LB, UB, RD, FN

FN IS THE FUNCTION FOR $X-1$ IN THE $1, X$ FORM OF THE ADJACENCY MATPIX.

$F N=N / 2$

$\mathrm{NN}=\mathrm{N}-1$

$P N=1000$

$\mathrm{C}$

C SEARCH FOR AN OPTIMAL EIGENVECTOR AMONG THOSE THAT CORRESPOND TO AN C EIGENVALUE OF MULTIPLICITY ONE.

DO $90 \quad I=1, N$

C

C

UNIQUELY MARK THE I TH NODE OF A AND THE NODES CONNECTED TO IT.

DO $10 \quad J=1, N$

$D A(J)=A(I, J)$

$A(J, J)=A(J, J)+D A(J)$

$A(I, J)=3 * F N$ 


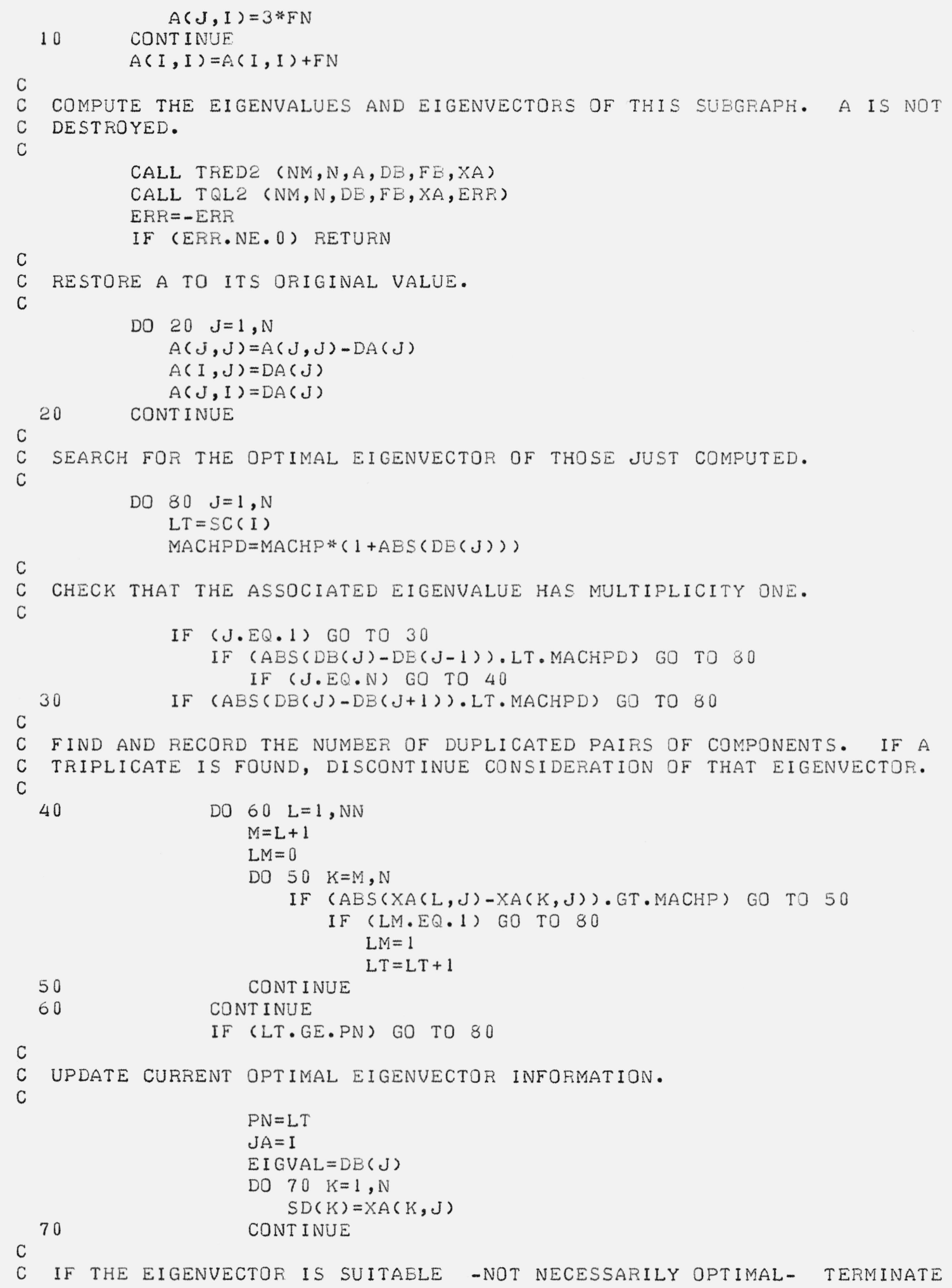


C

80 CONTINUE

90 CONTINUE

C IF NO SUITABLE EIGENUECTOR COULD BE FOUND, TERMINATE THIS PORTION

C OF THE ALGORITHM WITH APPROPRIATE MESSAGE.

C

IF (PN.LT.1000) GO TO 100

$E R R=3$

RETURN

100 MACHPD $=$ MACHP *(1+ABS (EIGVAL $))$

$L B=E I G V A L-M A C H P D$

$U B=E I G V A L+M A C H P D$

C

C STORE THE SELECTED EIGENUECTOR IN THE FIRST COLUMN OF XA.

$\mathrm{C}$

DO $110 \quad I=1, N$

$X A(I, 1)=S D(I)$

110 CONTINUE

C

C SELECTIVELY STORE THE PERTINENT INFORMATION HELD IN C AND SC IN ORDER

C TO FREE STORAGE FOR FUTURE USE.

C

$M=S C(J A)$

DO $120 \quad I=1, M$

20 CONTINUE

$G(I)=C(J A, I)$

C

C FIND AND EXAMINE THE CORRESPONDING EIGENUECTOR IN THE SUBGRAPHS OF B

C WHICH HAVE SPECTRA MATCHING THE SPECTRA GENERATED FROM THE SUBGRAPH

C OF A THAT PRODUCED THE OPTIMAL EIGENVECTOR.

C

$\mathrm{C}$

DO $170 \mathrm{~L}=1, \mathrm{M}$

C COPY B INTO C.

C

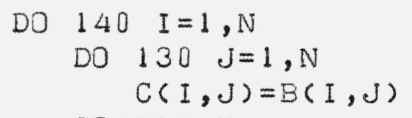

$130 \quad$ CONT INUE
140 CONTINUE

C

C FIND AND UNIQUELY MARK THE APPROPRIATE NODE IN B.

$\mathrm{C}$

$I=G(L)$

DO $150 \quad J=1, N$

$C(J, J)=C(J, J)+C(I, J)$

$C(I, J)=3 * F N$

150 CONTINUE

$C(J, I)=3 * F N$

$C(I, I)=C(I, I)+F N$

C

C FIND THE DESIRED EIGENVECTOR - C IS DESTROYED.

$\mathrm{C}$

CALL TREDI (NM, N, C, DA, DB, SC)

CALL BISECT ( $N, 0, D A, D B, S C, L B, U B, 1, P N, R D, L M, E R R, S D, S E)$ 


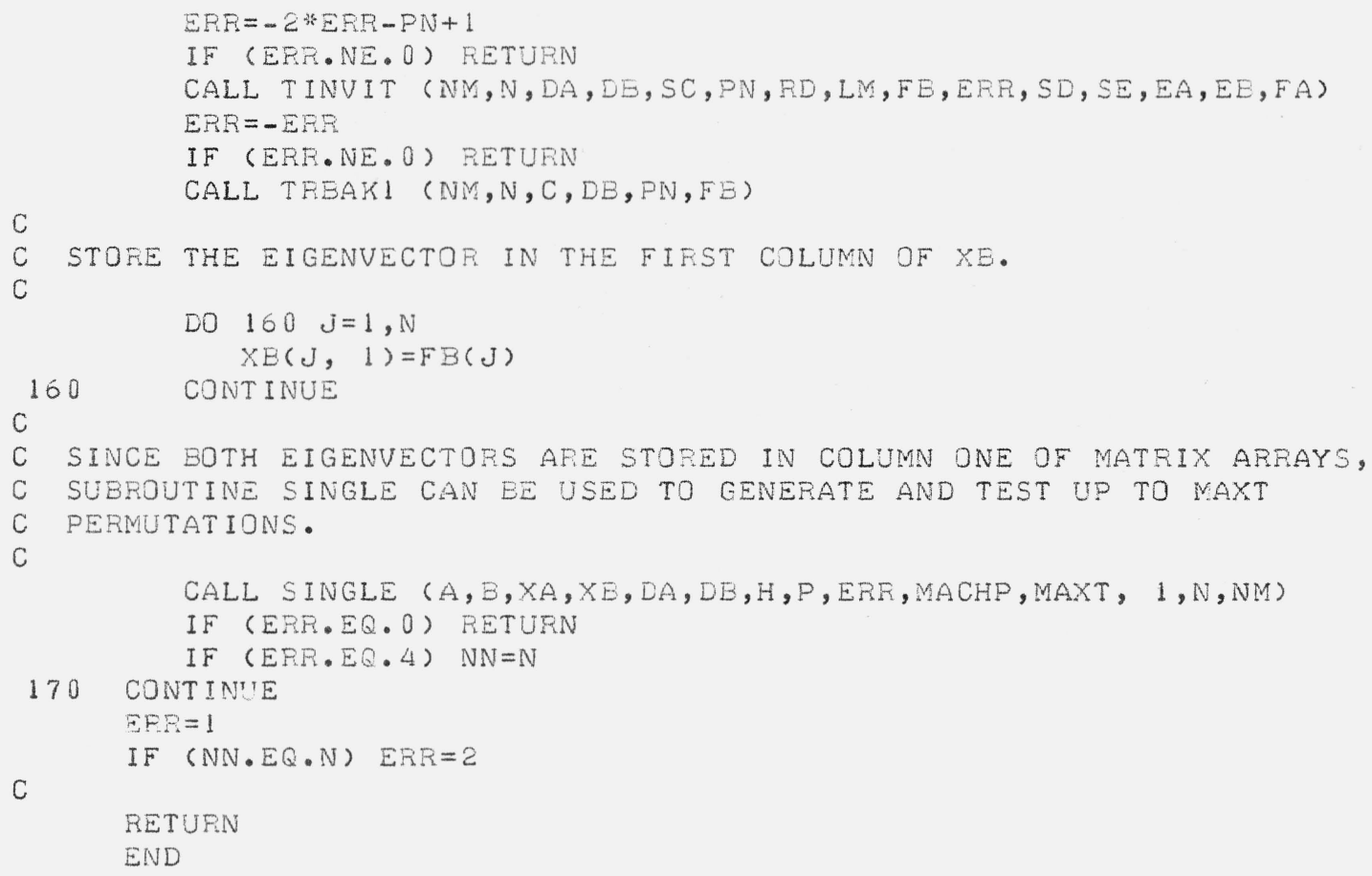




\section{Computational Experience}

The UNIVAC 1108 computer at the National Bureau of Standards was used to test the computer program on well over 200 pairs of graphs specifically selected for use because of their difficulty. The results have been encouraging. A Brookhaven National Laboratories group has compiled [2] a list of 149 pairs of nonisomorphic graphs of order varying from 7 to 10 that have 0,1 adjacency matrices with identical spectra. These cospectral graphs arise in connection with the energy field of a Heisenberg model ferromagnet. The computer program previously listed distinguished each of the 149 pairs in a total time of $3.9 \mathrm{cpu}$ seconds or, equivalently, each pair of graphs was determined to be nonisomorphic in approximately $0.026 \mathrm{cpu}$ seconds. Of the graphs, 109 failed the valence test, 28 the node duplication test, and the remaining 12 pairs failed to have 1,x modified adjacency matrices with identical spectra.

With some modification the algorithm can be programmed to sort a large set of graphs into subsets characterized by node valences, node duplication, $1, x$ modified adjacency matrix spectra, and in more difficult cases, submatrix spectra. Once this is accomplished, the groups in each subset can be pairwise checked for isomorphism using the program listed in this paper. This procedure was employed on a collection of 35 graphs ranging in order from 5 to 9 . Many of the graphs selected were known to be isomorphic and all had large automorphism groups, thus making it as difficult as possible for the algorithm to find permutations or to determine that none exist. By means of a simplified form of the sorting procedure, the 35 graphs were divided into 19 subsets in approximately $5 \mathrm{cpu}$ seconds. In this particular case, the spectra test was a sufficient condition for graph isomorphism. To be sure, however, permutations were generated between each pair of graphs in each subset. A total of 16 permutations were generated, 13 by means of SUBROUTINE SINGLE and 3 requiring SUBROUTINE DOUBLE, in a total time of $1.6 \mathrm{cpu}$ seconds.

None of the graphs yet tested, however, required the use of SUBROUTINE SUBVAL or SUBROUTINE SUBVEC. In response to a July, 1975 query about the existence of more challenging graphs, D. Corneil provided 16 pairwise nonisomorphic, order 25 graphs, any two of which required approximately 60 seconds on an IBM 370 (no model number was mentioned) to be distinguished by then current methods. The graphs were 3-strongly regular and stochastic with node valence 12 . None of the graphs has duplicate nodes and each had identical $1, x$ adjacency matrix spectra. The submatrix spectra test, however, successfully sorted the group into 8 subsets, each containing two graphs. It is interesting to note that the two graphs contained in each subset were duals of each other. This initial sorting was accomplished in just $86 \mathrm{cpu}$ seconds. When the algorithm was run on the 8 pairs of graphs, 5 were separated by means of the submatrix eigenvector test. The test was inconclusive on the remaining 3 pairs of graphs. The total run time was $150 \mathrm{cpu}$ seconds. Of this total, $86 \mathrm{cpu}$ seconds was spent distinguishing the 5 pairs and $64 \mathrm{cpu}$ seconds on the unsuccessful effort to resolve the final 3 pairs. In addition, the algorithm was applied to 5 of the graphs and constructed permutations. The program produced a permutation relating each of the 5 pairs of graphs by means of SUBROUTINE SUBVEC in $81 \mathrm{cpu}$ seconds.

Approximately 90 percent of the time required by the program is used in the calculation of eigenvalues and eigenvectors. Thus selection of optimal eigenvalue and eigenvector computing software is critical when time restrictions are sizeable. Since the EISPACK software referenced in the listing of the algorithm proved to be satisfactory for our needs, no significant effort was made to find more efficient software.

Tests on large numbers of random graphs were not conducted as it was felt that such tests would yield little meaningful data. Experience gained from working with the eigenvectors and eigenvalues of many graphs showed that only a relatively minute number of pairs of graphs exist for which the question of isomorphism is at all challenging for the algorithm and no such graphs are likely to occur in even a very large sample of randomly generated graphs. For the average pair of isomorphic graphs of order $n$, it is estimated that a permutation will be generated in well under $10^{-4} n^{3}$ cpu seconds UNIVAC 1108 time. Even faster times are achievable for random nonisomorphic pairs of graphs or through modifications in programming which first sort graphs by node valences, node duplicate structure $1, x$ modified adjacency matrix spectra, and in special cases (such as Corneil's collection of order 25 graphs) submatrix spectra, and then use the algorithm described in this paper to further reduce the subsets into classes for which the graphs are pairwise isomorphic.

Thus, with efficient application of the algorithm it is possible to divide a very large number of graphs into isomorphism equivalence classes in a reasonable amount of time. It is further possible to test pairs of very large graphs for isomorphism and if one exists, to generate permutations between two very large graphs. 


\section{References}

[1.] Baker, G., Drum shapes and isospectral graphs, J. Math. Physics 7, 2238-2242 (1966).

[2.] Baker, G., et al., A Data Compendium of Linear Graphs with Application to the Heisenberg Model, Brookhaven National Laboratory Report, 1967.

[3.] Corneil, D., and Gotlieb, C., An Efficient algorithm for graph isomorphism, JACM 17, 51-64 (1970).

[4.] Corneil, D., The Analysis of Graph Theoretical Algorithms, Proc. Fifth S-E Conference on Combinatorics, Graph Theory and Computing, pp. 3-38 (1974).

[5.] Harary, F., King, C., Mowshowitz, A., and Read, R., Cospectral graphs and digraphs, Bull. London Math. Soc. 3, 321-328 (1971).

[6.] Johnson, C., and Newman, M., A Note on Cospectral Graphs, submitted.

[7.] Mathon, R., and Corneil, D., Private Communications 1975-76.

[8.] Schmidt, D., and Druffel, L., A fast backtracking algorithm to test directed graphs for isomorphism using distance matrices, JACM 23, 433-445 (1976).

[9.] Smith, B., et al., Matrix Eigensystem Routines - EISPACK Guide, Lecture Notes in Computer Science 6, (Springer-Verlag, New York, 1974).

(Paper 80B4-457) 